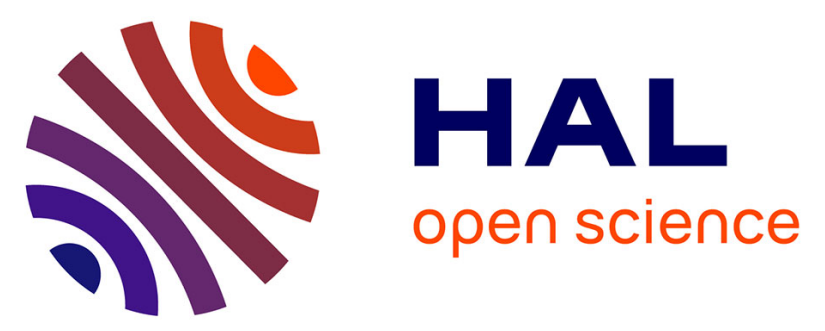

\title{
Co-occurrence and reproductive synchrony do not ensure hybridization between an alien tunicate and its interfertile native congener
}

Sarah Bouchemousse, Laurent Lévêque, Guillaume Dubois, Frédérique Viard

\section{- To cite this version:}

Sarah Bouchemousse, Laurent Lévêque, Guillaume Dubois, Frédérique Viard. Co-occurrence and reproductive synchrony do not ensure hybridization between an alien tunicate and its interfertile native congener. Evolutionary Ecology, 2015, 30 (1), pp.69-87. 10.1007/s10682-015-9788-1 . hal-01227971

\section{HAL Id: hal-01227971 \\ https://hal.sorbonne-universite.fr/hal-01227971}

Submitted on 12 Nov 2015

HAL is a multi-disciplinary open access archive for the deposit and dissemination of scientific research documents, whether they are published or not. The documents may come from teaching and research institutions in France or abroad, or from public or private research centers.
L'archive ouverte pluridisciplinaire HAL, est destinée au dépôt et à la diffusion de documents scientifiques de niveau recherche, publiés ou non, émanant des établissements d'enseignement et de recherche français ou étrangers, des laboratoires publics ou privés. 
1 Co-occurrence and reproductive synchrony do not ensure hybridization

2 between an alien tunicate and its interfertile native congener

3

4 Sarah Bouchemousse ${ }^{1,2,}$ *, Laurent Lévêque ${ }^{1,3}$, Guillaume Dubois ${ }^{1,2}$ and Frédérique $5 \operatorname{Viard}^{1,2, *}$

6 (1) Sorbonne Universités, UPMC Univ Paris 6, UMR 7144, Station Biologique de Roscoff, 7 Place Georges Teissier, 29680 Roscoff, France

8 (2) CNRS, UMR 7144, Equipe Div\&Co, Station Biologique de Roscoff, Place Georges 9 Teissier, 29680 Roscoff, France

(3) CNRS, FR 2424, Station Biologique de Roscoff, Place Georges Teissier, 29680 Roscoff,

France

*Correspondence : UMR7144, Equipe Diversité et Connectivité dans le paysage marin Côtier

(Div\&Co), CNRS-UPMC, Station Biologique de Roscoff, Place Georges Teissier, 29680

Roscoff, France

Email: sbouchemousse@sb-roscoff.fr, viard@sb-roscoff.fr

\section{EVOLUTIONARY ECOLOGY}

This article is available online (doi: 10.1007/s10682-015-9788-1) 


\section{Abstract}

Biological invasions can promote secondary contacts between related species and thus provide excellent case studies for investigating the joint ecological and evolutionary trajectories of interfertile taxa. Here, we studied two tunicates living in sympatry, and sometimes in syntopy, in the English Channel, Ciona intestinalis species A (presumed native to the NW Pacific) and species B (native to the N Atlantic). In addition to monitoring their coexistence over time, we examined the level of interspecific gene flow, a process that may increase the invasiveness of the non-native species. The sampling scheme was repeated twice a year for three years (6 distinct generations) to determine the relative abundance of the two species in 11 localities along the coasts of the English Channel and the Iroise Sea (covering $1600 \mathrm{~km}$ ) in Brittany, France. We examined 23,000 individuals, including 5,315 specimens for which reproductive status was determined. Four species-diagnostic molecular markers traced interspecific gene flow on a random subset of 3,048 individuals. Regardless of the sampling date, the two species co-occurred in most of the study sites, with species A showing higher frequency in the autumn. The regional pattern of seasonal variation in relative abundance of the two congeners appears to correspond to different thermal growth optima. Abrupt variations in environmental parameters can act synergistically and may favor the nonnative species locally. Despite syntopy, synchronous gamete production and successful in vitro interspecific crosses, only $4.3 \%$ individuals showed an admixed genome (i.e. footprint of present-day or past introgression events), most of them with a species A maternal lineage, of which only one was a putative first generation hybrid. Altogether, efficient barriers seem to prevent interspecific crosses between the two interfertile congeners in the wild: present-day hybridization may have less impact than competitive interactions on the fate of the two study species over their sympatric range. 


\section{Introduction}

Biological introductions (i.e. transport of species away from their native range via human activities) are modifying species ranges at an unprecedented rate and on global scales (e.g. in the marine environment, Molnar et al. 2008). Among the various ecological and evolutionary consequences of species introduction, hybridization between native and nonnative species can dramatically alter the evolutionary trajectories of both species (Allendorf et al. 2001). Hybridization sensu lato commonly refers to interspecific gene flow, including first-generation hybrids and repeated backcrossing of their offspring with parental species (Harrison 2012). Such interspecific gene flow between formerly allopatric taxa is not rare and can have diverse consequences (Allendorf et al. 2001), including an increased risk of extinction of the native species (Rhymer and Simberloff 1996; Fitzpatrick et al. 2010), increased invasiveness through, for instance, adaptive introgression mechanisms (Currat et al. 2008; Schierenbeck and Ellstrand 2009) and the emergence of new species (Abbott 1992). Hybridization facilitated by human activities has been studied mainly in plant species (e.g. Schierenbeck and Ellstrand 2009; Guo 2014) and to a lesser extent in animals (e.g. Fitzpatrick et al. 2010; Steeves et al. 2010), with only a few cases reported in marine systems (but see, for instance, Abudefduf vaigiensis and A. abdominalis, Coleman et al. 2014). However, marine species live in a dispersive environment and there is a large number of cryptic, co-existing native and non-native marine species (e.g. in tunicates; Bock et al. 2012; Perez-Portela et al. 2013). Furthermore, the increasing rate of marine biological invasions on the global scale facilitates numerous secondary contacts between allopatric taxa (Geller et al. 2010).

The recently described Ciona intestinalis species complex presents an interesting case to study. The nominal species $C$. intestinalis (Linnaeus, 1767) covers a complex of four cryptic species (Zhan et al. 2010). Two of them, C. intestinalis species A and C. intestinalis species B (hereafter referred to species A and species B, respectively) are now considered 
pseudo-cryptic species since the advent of morphological criteria to distinguish them (Sato et al. 2012). In addition, very recently, Brunetti et al. (2015) showed that species A displays morphological features specific to the formerly described Japanese species Ciona robusta Hoshino and Tokioka 1967, later synonymized under C. intestinalis, whereas species B fits with the $C$. intestinalis description by Millar (1953). These new alpha-taxonomy discoveries have not yet been implemented in the World Register of Marine Species (e.g. C. robusta is still a non-accepted name) and we will use 'species A' and 'species B' in the following text. Despite a substantial time elapsed since their divergence (estimated at around 4 Mya; Nydam and Harrison 2011; Roux et al. 2013), the two species are not reproductively isolated: viable and fertile F1 hybrids are easily produced under laboratory conditions (Sato et al. 2014). As in many other tunicates (Shenkar and Swalla 2011), the distribution range of these two species has expanded in the last two centuries due to their accidental introduction via human activities (Zhan et al. 2010). In particular, species A, has been recently introduced (ca. 15-20 years ago; Nydam and Harrison 2011; J.D.D. Bishop, personal communication) in the native European range of species B. Although the two species are widely distributed around the world, the western English Channel and the South of Brittany in the Northeast Atlantic (hereafter referred to as WEC) constitute the only confirmed region in which both species have been reported in sympatry.

Like many other ascidians (Airoldi et al. 2015), the nominal species $C$. intestinalis often forms well-established populations in artificial habitats (e.g. marinas with floating docks, commercial harbors and aquaculture installations). In their area of sympatry — the WEC - species A and species B can also live in syntopy (i.e. in the same locality, Fig. 1). However, because of the cryptic nature of these two species, most published ecological studies do not distinguish between them (Procaccini et al. 2011). Furthermore, C. intestinalis spp. is a model organism for evolutionary developmental biology research as well as 
phylogenetic studies. Nonetheless, ecological data are still lacking with regard to the recent discovery of the cryptic species. Due to its recent introduction in the WEC, species A experiences numerous, unprecedented biotic interactions and environmental changes that may affect its invasion dynamics (Blackburn et al. 2014). Consequently, there are many issues regarding the history, dynamics and fate of the recent introduction of species $\mathrm{A}$ in the native range of species $\mathrm{B}$, including the stability of co-occurrence in species that share the same habitat and localities, the intensity of interspecific competitive interactions, and the occurrence of introgression or a hybrid swarm in sympatry.

To address these issues, we surveyed 11 marinas located along the coasts of Brittany for three years, and examine six distinct generations (i.e. the spring and autumn generations of the same year). We carried out genetic analyses to investigate 1) regional and local variation in the relative abundance of species A and species B; 2) their potential to mate; and 3) the rate and direction of interspecific crosses in the wild.

\section{Field survey: sampling, morphological species identification and determination of}

\section{reproductive status}

We selected 11 marinas (out of 27) with floating pontoons located along the $1600 \mathrm{~km}$ long coastline of Brittany, France. These marinas were representative of a range of characteristics (i.e. open to the sea or closed during low tide (by means of tidal or sill gates)), fully marine or under freshwater (estuarine) influence; see Table S1 for details of each locality). In spring 2012, Ciona spp. populations were sampled in 10 marinas over two weeks (Fig. 2a). The same sampling was repeated five times, with an additional site (no. 11 in Fig. 2) in autumn 2012, spring and autumn 2013, and without sites nos. 10 and 11 (see Fig. 2) in spring and autumn 2014. The six sampling dates correspond to at least six different adult 
generations in European waters (e.g. Dybern 1965; Caputi et al. 2014). In each locality, ca. 200-300 adult individuals (Table 1 for details) were randomly collected along two pontoons during SCUBA diving operations over ca. $50 \mathrm{~m}$. Additionally, in most of the studied marinas (all except nos. 1, 2, 10 and 11, Fig. 2), seawater temperature was recorded using data loggers $\left(\right.$ TidbiT $\left.^{\circledR} \mathrm{v} 2\right)$ located at $1.5 \mathrm{~m}$ depth.

Following their collection, individuals were sedated with phenoxy-2-propanol (1:1000) for 20-30 min to facilitate species identification and excision of tissue samples. Species were identified using morphological criteria according to Sato et al. (2012). For each site, a random subset of 87 specimens ( $\mathrm{SD} \pm 12.6$; sample size detailed in Table $\mathrm{S} 2$ ) was used to examine the reproductive status (modified from ProtocolJRA1-04.00, http://www.assemblemarine.org/assets/ASSEMBLE-JRA1-Protocol-04.00mk.pdf). Given that both species are simultaneous hermaphrodites, although slighty protandrous, three sequential stages of individual development were recorded: immature individuals, presence of sperm only, and presence of sperm and oocytes. A piece of branchial basket was preserved individually in $100 \%$ ethanol for further genetic studies.

All statistical analyses were performed using $\mathrm{R}$ vers. 3.1.1 (R Development Core Team 2005). To investigate temporal and spatial variations in the relative abundance of both species, a linear mixed-effects model with a binomial error distribution was computed using the lme4 package (glmer function; Bates et al. 2014). Three sites (nos. 6, 10, 11, Fig. 2) with missing data or complete absence of species A were excluded. "Season" (spring and autumn generations) and "Year" (2012, 2013 and 2014) were considered as fixed factors. The factor "Sites" represented pseudo-replicates and was thus categorized as a random factor. In addition, pairwise comparisons among fixed factors were done. Comparisons of the proportion of individuals with sperm, or individuals producing sperm and oocytes, were tested using a Cochran-Mantel-Haenszel (CMH) chi squared test (Mantel 1963) using one 
contingency table per site, at each sampling date. Only localities with more than 10 individuals for each species were included in these analyses. For pairwise comparisons and CMH chi squared test, $P$-values were adjusted with a Bonferroni correction.

\section{Molecular identification of hybrids}

F1 hybrids and introgressed individuals (the two categories being referred to "admixed individuals" in the following text) cannot be discriminated morphologically (Sato et al. 2012). To identify them, species-diagnostic molecular markers were used on a random subset of individuals (average of 60 individuals \pm 6.9 (SD) per location and sampling date; Table 2) collected in 2012 and 2013. DNA extraction was performed with Nucleospin® 96 Tissue Kit according to the manufacturer's protocol (Macherey-Nagel, Germany).

Four species-diagnostic markers were used: one mitochondrial marker (mtCOI, cytochrome oxidase I) to identify the maternal lineage, and three nuclear loci, namely vAChTP (vesicular acetylcholine transporter), CesA (cellulose synthase) and Hox5 (intronic nuclear regions of Hox 5 gene) to identify the nuclear background. The Hox 5 locus was amplified using the primers and PCR protocol described in Caputi et al. (2007). For this locus, species-diagnostic alleles differ in their length and allele size was scored on simple agarose gels (2\%). For mtCOI, vAChTP and CesA, amplifications (protocols detailed in Nydam and Harrison, 2007, 2010) were followed by enzymatic digestions as explained in Nydam and Harrison (2011).

For each site and sampling date, the proportion of admixed individuals (i.e. displaying at least one alternative species-diagnostic allele) was computed across the four loci. To test for stability of admixture across samples, a Pearson's chi-squared test was used, and $P$-values were calculated using a Monte Carlo simulation with 5000 replicates. To further examine admixture patterns, a hybrid index per maternal lineage was computed for each sampling date 
using the above-described random subset and additional selected individuals from the field samples to reach a minimum number of 20 individuals per species when possible. The hybrid index was calculated by adding, over the three nuclear loci, the number of alleles specific to species B. It varies from zero to six: zero if each of the three nuclear loci are homozygous for the species A allele and six if the three nuclear loci display only species B alleles.

\section{Laboratory crosses}

Although the two species have been previously shown to be interfertile (e.g. Suzuki et al. 2005; Caputi et al. 2007; Sato et al. 2014), we carried out additional fertilization tests to ascertain that F1 hybrids could be easily produced with individuals from our study area. A series of bi-parental crosses (47 conspecific, 38 heterospecific and 23 self-crosses) were carried out using individuals sampled in autumn 2013 in the marinas of Aber Wrac'h (species B) and Moulin Blanc (species A and species B) (site nos. 6 and 7 in Fig. 2, respectively) following protocols available in Cirino et al. (2002) and Sato et al. (2014). Fertilization success was estimated by computing the proportion of eggs with cellular division after $1 \mathrm{~h}$ (i.e. fertilization rate). Following Sato et al. (2014), a linear mixed-effects model and pairwise comparisons were used to investigate differences in fertilization rate according to the type of cross (i.e. six categories: two heterospecific (with reverse parental roles for each species), two conspecific and two self-crosses) as a fixed factor. Because the same individuals were used in different crosses, a random effect of male genotype nested by female genotype was added.

\section{Results}

\section{Significant variation in the relative abundance of the two species across generations}

In the first study generation (i.e. spring 2012), species A and species B co-occurred in 8 localities out of the 10 surveyed, although species A was never abundant (Fig. 2). Detailed 
values per site and sampling date are given in Table 1. Although abundance varied across localities, regionally $6.0 \%$ of the 2,316 individuals were morphologically identified as species A in spring 2012. This spatial pattern changed dramatically in autumn 2012 with $32.2 \%$ of the individuals identified as species A out of the 3,678 individuals collected in 11 marinas (Fig. 2). Similar patterns were observed in 2013 and 2014 with an increase in the relative abundance of species A in autumn (Table 1, Fig. 2).

At the locality level, 7 of the 11 studied marinas showed temporal variation similar to the regional pattern, with some showing particularly strong contrasts between spring and autumn generations (e.g. Perros Guirec; no. 3 in Fig. 2). The remaining four localities showed distinct features. Moulin Blanc (no. 7, Fig. 2) showed a different pattern in 2013, with spring abundance of species A (35.8\%) being much higher than in autumn (2.2\%). In Roscoff (no. 5, Fig. 2), a regular decrease in species A was observed over the course of the survey, starting in spring 2012 with $8.8 \%$ of species A dropping to $0 \%$ during the last four sampling dates. Conversely, the presence of species A was first recorded in St Malo (no. 1, Fig. 2) during the last sampling date (autumn 2014; $1.1 \%$ of species A). Finally, species A was absent in one site (Aber Wrac'h, no. 6 in Fig. 2) on all sampling dates.

Altogether, a significant interaction was found between season and year (Table 3a) which reflects 1) an increase in the relative abundance of species A in autumn compared with spring of the same year and 2) a higher relative abundance of species A in 2012 compared with the following two years (Fig. 2).

\section{Synchronous gamete production and successful fertilization between the two species}

The reproductive status of individuals at each sampling date for both study species is illustrated with ternary diagrams (Fig. 3): the distribution of the three categories varied among species and localities. When comparing species for the proportion of individuals with sperm 
only, there were significant differences in spring and autumn $2013(P<0.001$ and $P<0.001$, respectively) and in autumn $2014(P=0.032)$. The proportion of individuals with both types of gametes showed a similar pattern with no significant difference except for two dates (in autumn 2012 and autumn 2014; $P<0.001$ ). Altogether, regardless of the species, a high proportion of individuals produced gametes on all sampling dates. For example, in Trébeurden (no. 4, Fig. 2) in spring 2012, $100 \%$ of species A individuals and $84 \%$ of species B individuals showed both sperm and oocytes. Detailed values per site and sampling date are provided in Table S2.

There were significant differences in fertilization rates when comparing cross type (Fig. 4, Table 3b). In particular, selfing success was very poor. Fertilization rates of heterospecific crosses with oocytes from species B did not differ from those of the two conspecific crosses (ca. 80\%, Fig. 4). Fertilization rates dropped to very low values $(<6 \%)$ when species A was the female parent (Fig. 4).

\section{mtDNA-based species identification}

Altogether, 3,048 individuals collected during the four surveys carried out in 2012 and 2013 were genotyped over four loci including one mitochondrial marker for identifying the maternal lineage. Only 33 of them $(1.08 \%)$ showed discordance between morphological and mitochondrial identification, indicating a close association between maternal type and species assignment based on morphology. During the 2012 and 2013 field surveys, 90 individuals out of $15,463(0.59 \%)$ were morphologically recorded as "unidentified" (Table 1); most (82\%) of these showed a species B maternal lineage.

\section{A unique putative F1 hybrid and little genetic admixture in the wild}


Only 131 of the 3,048 individuals (4.3\%) showed an admixed genome and all of them displayed very low hybrid index values (Fig. 5). In addition, only one (0.03\%) individual was possibly a first-generation hybrid (i.e. heterozygote across the three nuclear loci). This putative F1 hybrid displayed a species B maternal lineage and was found in Perros Guirec (no. 3, Fig. 2) in autumn 2013.

Regardless of maternal type, at the regional level, the proportion of admixture varied from $0.8 \%$ (spring 2013) to $6.3 \%$ (autumn 2012). A slightly higher rate of admixture was found in the autumn generations compared with the spring generations (Table 1). The admixture rate varied slightly across localities (Table 1). In particular, in localities where the two species co-occurred, admixed individuals were frequently found. For instance during the first sampling date 1.6\% in St Quay, Trébeurden and Moulin Blanc (nos. 2, 4 and 7, Fig. 2) and 9.7\% in Perros Guirec and Roscoff (nos. 3 and 5, Fig. 2). In contrast, no admixed individuals were observed in the locality where species A was absent throughout the survey (Aber Wrac'h, no. 6 in Fig. 2). These variations are, however, explained by differences in admixture patterns between individuals with different maternal backgrounds (Table 2). Large differences in the admixture proportion were indeed observed between the two groups with $82.4 \%$ of the 131 of individuals showing an admixed genome characterized by a species $\mathrm{A}$ maternal lineage. In addition, the admixture proportion of individuals with a species A maternal lineage was stable across localities and time (all localities and sampling date comparison, $P=0.178)$ and across localities at each sampling date separately $(P>0.05$ except in autumn 2013: $P=0.032$ ). In contrast, the proportion of admixed individuals with a species $B$ maternal lineage was variable across localities and time (all localities and sampling date comparisons, $P=0.002)$ and across localities for each sampling date $(P<0.05$ except in spring 2013: $P=0.129$ ). Altogether, these results show that most of the variation in admixture among 
localities or sampling dates (Table 1) is due to variation in the relative abundance of species

A, which showed the highest admixture rate.

272

\section{Discussion}

\section{The non-native tunicate Ciona intestinalis species $A$ is well established}

Based on the morphological examination of 23,000 individuals covering six different generations, we documented the durable establishment of the non-native species (NNS) $C$. intestinalis species A along the coasts of Brittany, ca. 15-20 years after the first reports of its introduction in the WEC. The first detailed study on the co-occurrence of species A and species B in the English Channel (Nydam and Harrison 2011) revealed no samples of species A specimens during a follow-up survey (in 2009, two years after their first survey), interpreted as a possible decline of the NNS in the localities surveyed. This decline was not confirmed in our study. Our data, combined with those of Nydam and Harrison (2011), illustrate the importance of temporal monitoring over a substantial time window, particularly during the establishment stage, as well as during different seasons for short-lived species.

Despite the sustainable regional establishment of species A, there was local population instability: for instance, the Roscoff marina showed a steady decline leading to complete disappearance. Local population dynamics are likely to be unstable in this short-lived and recently introduced NNS, as observed in other introduced regions (e.g. Saldanha Bay in South Africa, Rius et al. 2011). Such major changes in site occupancy and local abundance in just a few years have already been documented in other NNS discovered in the English Channel (e.g. Bishop et al. 2014). Many environmental and biotic mechanisms influence the successful and durable establishment of NNS (Blackburn et al. 2014), including competitive interactions 
mechanism may be particularly important here because the non-native species A co-occurs with its congener (Fig. 1).

\section{Seasonal variation in species abundance: the outcome of competition in a changing}

\section{environment}

Regular field work, sampling and monitoring as well as panels experiments examining settlement dynamics of Ciona sp. (S. Bouchemousse, L. Lévêque, F. Viard, unpublished data) showed that spring and autumn generations are two separate generations, for the two study species. This is in agreement with the few data documenting the number of generations per year in the study area (Dybern 1965 in the North Atlantic for species B). By examining these two distinct generations of the same year, during three years, we documented a significant increase in the relative abundance of species A in autumn. Adults sampled in autumn likely correspond to juveniles that had settled from spring to early summer, when sea water temperatures increase from ca. $12^{\circ} \mathrm{C}$ in April to ca. $18^{\circ} \mathrm{C}$ in August-September in the study area (Figure S1). Conversely, adults sampled in spring likely correspond to juveniles that have settled in late summer / early fall, and which survive across the winter season (S. Bouchemousse, L. Lévêque, F. Viard, unpublished data). Seawater temperature greatly influences the development, growth and survival of Ciona intestinalis spp. (Dybern 1965; Marin et al. 1987), with species A and species B reported as warm-water and cold-water species, respectively (Procaccini et al. 2011; Caputi et al. 2014). We observed higher growth rates at $17^{\circ} \mathrm{C}$, for species $\mathrm{A}$ than species $\mathrm{B}$ during laboratory experiments (data not shown), confirming previous findings (Petersen et al. 1995) based on the growth rate of the nominal species $C$. intestinalis in localities where only species A or species B are now reported (e.g. at $15^{\circ} \mathrm{C}$, growth rate varies between 2 and $3 \%$ in length per day for Japanese populations (species A) and between 0.7 and $1.1 \%$ per day for individuals from Scotland (species B)). In 
the study area, temperatures above $15^{\circ} \mathrm{C}$ are only observed from June to October (Figure $\mathrm{S} 1$ ). It is also noteworthy that in the localities with the lowest maximum values of sea water temperatures (i.e. Aber Wrac'h and Roscoff, with a maximum always below $17^{\circ} \mathrm{C}$ ) $C$. intestinalis species A has never been observed or declined up to disappearance. The observed seasonal variations may thus partly result from spatial competition among species A and B. The autumn generation of species A may have a competitive advantage, due to its faster growth rate during the warmer season.

Although temperature is likely the main environmental driver of the seasonal dynamics of the two congeners at a regional scale, other factors can drive local population dynamics. In particular, episodes of low salinity, due to rainfall and river inputs, can decrease survival of $C$. intestinalis (Lambert and Lambert 1998). Such perturbation events due to abrupt variations in environmental parameters have been recorded in our study area, as illustrated in Figure S2 for the marina of Moulin Blanc (no. 7 in Fig. 2), where additional monitoring (independent of our study; L. Lévêque, unpublished data) for C. intestinalis spp. abundance and salinity was carried out in 2013-2014. Salinity declined sharply and subsequently Ciona spp. died off massively during winter months from January to March 2014. Synergistic effects between temperature and salinity may explain the very high percentage of species A observed in some localities such as Perros-Guirec (up to 90\%; Fig. 2): this marina is closed off from the sea at low tide and remains several days without seawater renewal during neap tides such that 1) salinity can rapidly decrease in winter (due to rainfall) and 2) temperature can increase on the surface in summer (Figure S1). After winter die-offs of both species, due both to low temperatures and low salinity episodes, increasing seawater temperature may favor a more rapid colonization of species A over species B, taking into account its faster growth rate, on pontoons from adjacent sources (e.g. pillars, sea-wall), giving locally and at some particular season, a competitive advantage to species A over 
species B. Conversely, Roscoff is an open, fully marine marina in the coldest part of the

345 Brittany coastline (i.e. $13^{\circ} \mathrm{C}$ annual average, Gallon et al. 2014). No massive mortality of Ciona intestinalis spp. has ever been observed and low temperatures may favor the

347 development of species B, leading to competitive exclusion of species A.

Altogether, our study suggests that, with a few exceptions, environmental conditions in the study sites meet the niche requirements of the NNS species, though local variations in environmental parameters may favor one or the other of the two species, and thus may influence the outcome of competitive interactions among them. In particular, species A, thanks to its faster growth rate, may have a better adaptive potential than species B for (re)colonizing substrates during warmer seasons after disturbances due to variations in environmental factors, like a sharp decline in salinity after rains. Over larger temporal scales, the predicted increase of sea surface temperature (i.e. $0.35^{\circ} \mathrm{C}$ per decade; Gallon et al. 2014) and winter rainfalls (Ouzeau et al. 2014) in Brittany, due to climate change, could promote a substantial increase of the relative abundance of the NNS compared with its native congener in its introduced range.

\section{Efficient barriers prevent hybridization in the wild}

Sexually mature, gamete-producing individuals occurred simultaneously in the two study species which are interfertile and live in syntopy in most of the study localities. Despite these features that are expected to favor hybridization, the admixture rate was very low (4.3\%) and only one putative F1 hybrid was observed in this study on more than 3,000 individuals, confirming previous studies (4.2\% in localities of the WEC, Nydam and Harrison 2011; 6.3\% in one British locality, Sato et al. 2014). Ecological and/or genetic barriers thus seem to be at play and limit hybridization between the two species in the wild in Brittany. The success of interspecific fertilization in laboratory conditions (Fig. 4) seemingly suggests that 
post-zygotic isolation mechanisms act in the wild through a reduction in hybrid fitness (Abbott et al. 2013). However, Sato et al. (2014) showed that F1 hybrids are viable and produce functional gametes, suggesting that hybrid depression, if any, is expressed at an earlier stage (e.g. larvae or juveniles). However, preliminary findings from a molecular study of juveniles of species A and species B in four marinas of the WEC (nos. 4, 5, 7 and 8; Fig. 2) showed rates of admixture similar to those observed in adults (S. Bouchemousse, L. Lévêque, F. Viard, unpublished data). Pre-zygotic isolation mechanisms can enhance assortative mating; however, given the close contact (see Fig. 1), habitat segregation and behavior cannot be efficient reproductive isolation mechanisms. Differences in the timing of reproductive development, as suggested by Sato et al. (2014), are also unlikely because we observed a high proportion of individuals producing gametes in both species and each sampling date. Gamete release occurs over several days or even weeks (Carver et al. 2003), invalidating any consideration of slight shifts in the timing of gamete release in light of the short survival time of the gametes in seawater (i.e. $16 \mathrm{~h}$ after release for sperm and $30 \mathrm{~h}$ for oocytes; Svane and Havenhand 1993). Assortative fertilization, facilitated by species-specific chemical attraction, can be a key mechanism for reproduction in broadcast-spawning marine invertebrates in marine systems (Palumbi 1994). This mechanism has been described already within species complexes, for instance in two tropical sea urchins of the Echinometra species complex (Geyer and Palumbi 2005) and in two mussels of the Mytilus species complex (Bierne et al. 2002). Laboratory gamete choice experiments are needed to investigate this mechanism in the C. intestinalis species complex.

\section{The source of admixture: historical or contemporary processes?}

In the laboratory, F1 hybrids are easily obtained in one direction only, i.e. with species B oocytes (Fig. 4). Asymmetrical interspecific fertilization success is common, including in 
free-spawning marine invertebrates (e.g. Rawson et al. 2003; Geyer and Palumbi 2005). The direction of this asymmetry was however unexpected based on the observed admixture rates that we computed according to the maternal lineage (82.4\% of the 131 admixed individuals showed a species A maternal lineage). There are two possible explanations of this discrepancy between laboratory and field data. First, the few offspring produced by the least productive heterospecific crosses (i.e. a species A female crossed with a species B male) may be particularly fertile and vigorous. Similar situations with successful hybrids produced by parental combinations with low fertilization success have already been described, even in marine systems (e.g. Blum et al. 2010). This process may foster adaptive introgression of the NNS (species A) and/or drive hybrids to replace parental species (e.g. Rosenfield et al. 2004; Schierenbeck and Ellstrand 2009). Second, conditions that promote successful crosses in the laboratory may not be the conditions found in the wild (Sato et al. 2014). Monitoring survival of hybrid offspring obtained from experimental crosses is one way to test these two hypotheses. It is also interesting to note that the direction of the asymmetry is variable across studies: the direction observed here is in agreement with what has been reported by Caputi et al. (2007) but not with Sato et al. (2014), although in both studies some of the crosses involved individuals from the North Atlantic. Factors promoting (preventing) the hybridization success are potentially numerous, and among them the origin and the genetic background, in particular the introgression profiles (see below), may be important factors to consider in future studies.

Alternatively, from a conceptually different viewpoint, observed admixture may reflect the footprint of a previous secondary contact between species A and species B (Roux et al. 2013). Roux et al. (2013) compared various speciation models (e.g. divergence models with or without interspecific gene flow) using Approximate Bayesian Computations based on full transcriptomes of species A and species B (10 individuals for each). The best model to 
explain the data was a model of divergence with gene flow resulting from a secondary contact between the two species after their primary divergence (4 Mya ago). During this secondary contact, ca. $20 \%$ of loci presumably crossed the species barrier in both directions (Roux et al. 2013). The authors then estimated the age of this secondary contact between 4,300 and 56,800 years ago. Many secondary contacts have been documented in marine systems during this period which corresponds to the end of the Pleistocene (Maggs et al. 2008; Geller et al. 2010). The number of studies showing interspecific gene flow following these secondary contacts also recently increased (Abbott et al. 2013, see Becquet et al 2012 for an example). In this context, past hybridization is very plausible explanation of our results because it can account for 1) the discrepancy observed between laboratory and field experiments; 2) the temporal and spatial stability of the proportion of admixed individuals for species A; and 3) the complex evolutionary history of the two study cryptic species (Roux et al. 2013). Although historical processes may explain most of the admixture observed, contemporary interspecific gene flow remains possible based on our results in two localities: in St Malo, no admixed individuals were observed until autumn 2013 following the colonization of this locality by species A and in Roscoff, admixed individuals were observed in 2012, but none afterwards when species A disappeared. Finally, at Aber Wrac'h, the only locality where no species A specimens were ever observed, did not show any admixed specimens. Furthermore — and interestingly — in St Malo and Aber Wrac'h, all admixed individuals displayed a species B maternal lineage, as did the only putative F1 hybrid found in our study (in Perros Guirec).

Altogether, our results suggest that past secondary contacts influenced the introgression rates measured here and rare contemporary hybridizations in the wild account mainly for the admixed individuals with a species B maternal background, in agreement with laboratory assays. The status of the presumed species diagnostic markers used so far (Caputi et al. 2007; Nydam and Harrison 2011; Sato et al. 2014; this study) need to be re-evaluated 
because the three loci behave differently: CesA and vAChTP highlight admixture in species B maternal backgrounds whereas Hox5 revealed admixture with species A maternal backgrounds (see Table S3). Although not discernable in our laboratory crosses (or in the literature, Caputi et al. 2007), we suggest that Hox5 crossed the species barrier a long time ago, in contrast to the two other loci (similar to the Glu locus which was mistakenly considered as a diagnostic marker of Mytilus species, Borsa et al. 2012). High-throughput genotyping based on SNPs are currently in progress to better investigate the fate of the introgression hot-spots defined by Roux et al. (2013) and the true extent of contemporary hybridization in wild Ciona populations.

In conclusion, our study highlights the importance of temporal monitoring adapted to the life cycle and the generation time of short-lived NNS. This type of monitoring is critical for early-warning and accurate assessments of the durable establishment of introduced species. Our results also illustrate how difficult it is to predict the outcome of humanmediated introductions, even in supposedly well-known model species: we expected to find a large proportion of hybrids and introgression events between species A and species B, but only rare events (if any) were uncovered despite extensive sampling. Our results pave the way for future research on the reproductive isolation mechanisms acting in the wild between these model organisms, as well as on the processes that can sustain long-term co-occurrence of two functionally similar and congeneric species living in syntopy.

\section{Acknowledgments}

We are very grateful to the divers of the Marine Operations department (Service Mer \& Observation) at the Roscoff Biological Station for help in the field and to M. Danielo for assistance in data acquisition. FV thanks M. Nydam for her recommendations regarding 
469 molecular protocols. We are thankful for the numerous marina operators who provided access 470 to pontoons and permission to carry out this study. We acknowledge S. Le Cam and T. 471 Broquet for advices regarding statistical analyses, N. Bierne for stimulating discussions about 472 hybridization and introgression processes, and C. Lejeusne and T. Comtet for comments on 473 earlier versions of this manuscript. This work was supported by the Interreg IVa Marinexus 474 program and the ANR project HYSEA (no. ANR-12-BSV7-0011).

475

476 


\section{References}

Abbott RJ (1992) Plant invasion, interspecific hybridization and the evolution of new plant taxa. Trends Ecol Evol 7:401-405.

Abbott R, Albach D, Ansell S et al (2013) Hybridization and speciation. J Evol Biol 26:229246.

Airoldi L, Turon X, Perkol-Finkel S et al (2015) Corridors for aliens but not for natives: effects of marine urban sprawl at a regional scale. Divers Distrib doi: 10.1111/ddi.12301

Allendorf FW, Leary RF, Spruell P et al (2001) The problems with hybrids: setting conservation guidelines. Trends Ecol Evol 16:613-622.

Alpert P (2006) The advantages and disadvantages of being introduced. Biol Invasions 8:1523-1534.

Bates D, Maechler M, Bolker B et al (2014) lme4: Linear mixed-effects models using Eigen and S4. R package version 1.1-7 http:/CRAN.R-project.org/package=lme4.

Becquet V, Simon-Bouhet B, Pante E et al (2012) Glacial refugium versus range limit: Conservation genetics of Macoma Balthica, a key species in the Bay of Biscay (France). J Exp Mar Biol Ecol 432-433:73-82.

Bierne N, David P, Boudry P et al (2002) Assortative fertilization and selection at larval stage in the mussels Mytilus edulis and M. galloprovincialis. Evolution 56:292-298.

Bishop JDD, Wood CA, Lévêque L et al (2014) Repeated rapid assessment surveys reveal contrasting trends in occupancy of marinas by non-indigenous species on opposite sides of the western English Channel. Mar Pollut Bull, doi:10.1016/j.marpolbul.2014.11.043. 
Blackburn TM, Essl F, Evans T et al (2014) A unified classification of alien species based on the magnitude of their environmental impacts. PLoS Biol 12, doi:10.1371/journal.pbio.1001850

Blum MJ, Walters DM, Burkhead NM et al (2010) Reproductive isolation and the expansion of an invasive hybrid swarm. Biol Invasions 12:2825-2836.

Bock DG, MacIsaac HJ, Cristescu ME (2012) Multilocus genetic analyses differentiate between widespread and spatially restricted cryptic species in a model ascidian. Proc R Soc B 279:2377-2385.

Borsa P, Rolland V, Daguin C (2012) Genetics and taxonomy of Chilean smooth-shelled mussels, Mytilus spp. (Bivalvia: Mytilidae). C R Biol 335:51-61.

Brunetti R, Gissi C, Pennati R et al (2015) Morphological evidence that the molecularly determined Ciona intestinalis type A and type B are different species: Ciona robusta and Ciona intestinalis. J Zoolog Syst Evol Res, doi: 10.1111/jzs.12101

Caputi L, Andreakis N, Mastrototaro F et al (2007) Cryptic speciation in a model invertebrate chordate. Proc Natl Acad Sci USA 104:9364-9369.

Caputi L, Crocetta F, Toscano F et al (2014) Long-term demographic and reproductive trends in Ciona intestinalis sp. A. Mar Ecol 36:118-128.

Carver CE, Chisholm A, Mallet AL (2003) Strategies to mitigate the impact of Ciona intestinalis (L.) biofouling on shellfish production. J Shellfish Res 22:621-631.

Cirino P, Toscano F, Caramiello D et al (2002) Laboratory culture of the ascidian Ciona intestinalis (L.): a model system for molecular developmental biology research. $\begin{array}{llll}\text { Marine } & \text { Models } & \text { Electronic } & \text { Record. }\end{array}$ http://www.mbl.edu/html/BB/MMER/CIR/CirTit.html 
523 Coleman RR, Gaither MR, Kimokeo B et al (2014) Large-scale introduction of the Indo-

524

525

526

527

528

529

530

531

532

533

534

535

536

537

538

539

540

541

542

543

544

545

546

547 Pacific damselfish Abudefduf vaigiensis into Hawai'i promotes genetic swamping of the endemic congener A. abdominalis. Mol Ecol 23:5552-5565.

Currat M, Ruedi M, Petit RJ et al (2008) The hidden side of invasions: Massive introgression by local genes. Evolution 62:1908-1920.

Dybern BI (1965) The life cycle of Ciona intestinalis (L.) f. typica in relation to the environmental temperature. Oikos 16:109-131.

Fitzpatrick BM, Johnson JR, Kump DK et al (2010) Rapid spread of invasive genes into a threatened native species. Proc Natl Acad Sci USA 107:3606-3610.

Gallon RK, Robuchon M, Leroy B et (2014) Twenty years of observed and predicted changes in subtidal red seaweed assemblages along a biogeographical transition zone: inferring potential causes from environmental data. J Biogeogr 41:2293-2306.

Geller JB, Darling JA, Carlton JT (2010) Genetic perspectives on marine biological invasions. Annu Rev Mar Sci 2:367-393.

Geyer LB, Palumbi SR (2005) Conspecific sperm precedence in two species of tropical sea urchins. Evolution 59:97-105.

Guo Q (2014) Plant hybridization: the role of human disturbance and biological invasion. Divers Distrib 20:1345-1354.

Harrison RG (2012) The language of speciation. Evolution 66:3643-3657.

Lambert CC, Lambert G (1998) Non-indigenous ascidians in southern California harbors and marinas. Mar Biol 130:675-688.

Maggs CA, Castilho R, Foltz D et al (2008) Evaluating signatures of glacial refugia for North Atlantic benthic marine taxa. Ecology 89:S108-S122.

Mantel N (1963) Chi-square tests with one degree of freedom: Extensions of the MantelHaenszel Procedure. J Am Statist Assoc 58:690-700. 
Marin MG, Bressan M, Beghi L et al (1987) Thermo-haline tolerance of Ciona intestinalis (L., 1767) at different developmental stages. Cah Biol Mar 28:47-57.

Millar RH (1953) Ciona. In: Colman JS (ed.) L.M.B.C. Memoirs of Typical British Marine Plants and Animals, XXV. Liverpool University Press, Liverpool, pp 123.

Molnar JL, Gamboa RL, Revenga C et al (2008) Assessing the global threat of invasive species to marine biodiversity. Front Ecol Environ 6:485-492.

Nydam ML, Harrison RG (2007) Genealogical relationships within and among shallow-water Ciona species (Ascidiacea). Mar Biol 151:1839-1847

Nydam ML, Harrison RG (2010) Polymorphism and divergence within the ascidian genus Ciona. Mol Phylogenet Evol 56:718-726.

Nydam ML, Harrison RG (2011) Introgression despite substantial divergence in a broadcast spawning marine invertebrate. Evolution 65:429-442.

Ouzeau G, Déqué M, Jouini M et al (2014) Scénarios régionalisés - édition 2014 - pour la métropole et les régions d'outre-mer. In : Jouzel J (ed) Le climat de la France au XXI ${ }^{\mathrm{e}}$ siècle. Direction Générale de l'Energie et du Climat 4: 62.

Palumbi SR (1994) Genetic divergence, Reproductive isolation and marine speciation. Annu Rev Ecol Syst 25:547-572.

Perez-Portela R, Arranz V, Rius M et al (2013) Cryptic speciation or global spread? The case of a cosmopolitan marine invertebrate with limited dispersal capabilities. Sci Rep 3, doi:10.1038/srep03197.

Petersen JK, Schou O, Thor P (1995) Growth and energetics in the ascidian Ciona intestinalis. Mar Ecol Prog Ser 120:175-184.

Procaccini G, Affinito O, Toscano F et al (2011) A new animal model for merging Ecology and Evolution. In: Pontarotti P (ed) Evolutionary Biology: concepts, biodiversity, macroevolution and genome evolution. Springer-Verlag, Berlin, pp 91-106 
573 R Development Core Team (2005) R: A language and environment for statistical computing. R Foundation for Statistical, Vienna, Austria. ISBN 3-900051-07-0, URL: http://www.R-project.org.

Rawson PD, Slaughter C, Yund, PO (2003) Patterns of gamete incompatibility between the blue mussels Mytilus edulis and M. trossulus. Mar Biol 143:317-325.

Rhymer JM, Simberloff D (1996) Extinction by hybridization and introgression. Annu Rev Ecol Syst 27:83-109.

Rius M, Heasman KG, McQuaid CD (2011) Long-term coexistence of non-indigenous species in aquaculture facilities. Mar Pollut Bull 62:2395-2403.

Rosenfield JA, Nolasco S, Lindauer S et al (2004) The role of hybrid vigor in the replacement of Pecos pupfish by its hybrids with sheepshead minnow. Conserv Biol, 18 15891598.

Roux C, Tsagkogeorga G, Bierne $\mathrm{N}$ et al (2013) Crossing the species barrier: genomic hotspots of introgression between two highly divergent Ciona intestinalis species. Mol Biol Evol 30:1574-1587.

Sato A, Satoh N, Bishop JDD (2012) Field identification of 'types' A and B of the ascidian Ciona intestinalis in a region of sympatry. Mar Biol 159:1611-1619.

Sato A, Shimeld SM, Bishop JDD (2014) Symmetrical reproductive compatibility of the two species in the Ciona intestinalis (Acidiacea) species complex, a model for marine genomics and developmental biology. Zool Sci 31:369-374.

Schierenbeck KA, Ellstrand NC (2009) Hybridization and the evolution of invasiveness in plants and other organisms. Biol Invasions 11:1093-1105.

Shenkar N, Swalla BJ (2011) Global diversity of Ascidiacea. PLoS ONE 6, doi:10.1371/journal.pone.0020657.

Simberloff D, Stiling P (1996) How risky is biological control? Ecology 77:1965-1974. 
598 Steeves TE, Maloney RF, Hale ML, Tylianakis JM et al (2010) Genetic analyses reveal 599 hybridization but no hybrid swarm in one of the world's rarest birds. Mol Ecol $600 \quad 19: 5090-5100$.

601 Suzuki MM, Nishikawa T, Bird A (2005) Genomic approaches reveal unexpected genetic 602 divergence within Ciona intestinalis. J Mol Evol 61:627-635.

603 Svane I, Havenhand JN (1993) Spawning and dispersal in Ciona intestinalis (L.). Mar Ecol 604 $14: 53-66$

605 Zhan A, Macisaac HJ, Cristescu ME (2010) Invasion genetics of the Ciona intestinalis species 606 complex: from regional endemism to global homogeneity. Mol Ecol 19:4678-4694. 
Table 1. Sample size $\left(\mathrm{N}_{\text {tot }}\right)$, number of individuals unidentified based on morphological criteria $\left(\mathrm{N}_{\text {uni }}\right)$, and percentage of Ciona intestinalis species A specimens (based on morphology; $\%_{\mathrm{spA}}$ ), for each study site and sampling date. The overall introgression rate (i.e. proportion of individuals showing an admixed multilocus genotype whatever their maternal lineage; $\%_{\text {mix }}$ ) is indicated for the four surveys for which there were molecular data (i.e. all except in 2014).

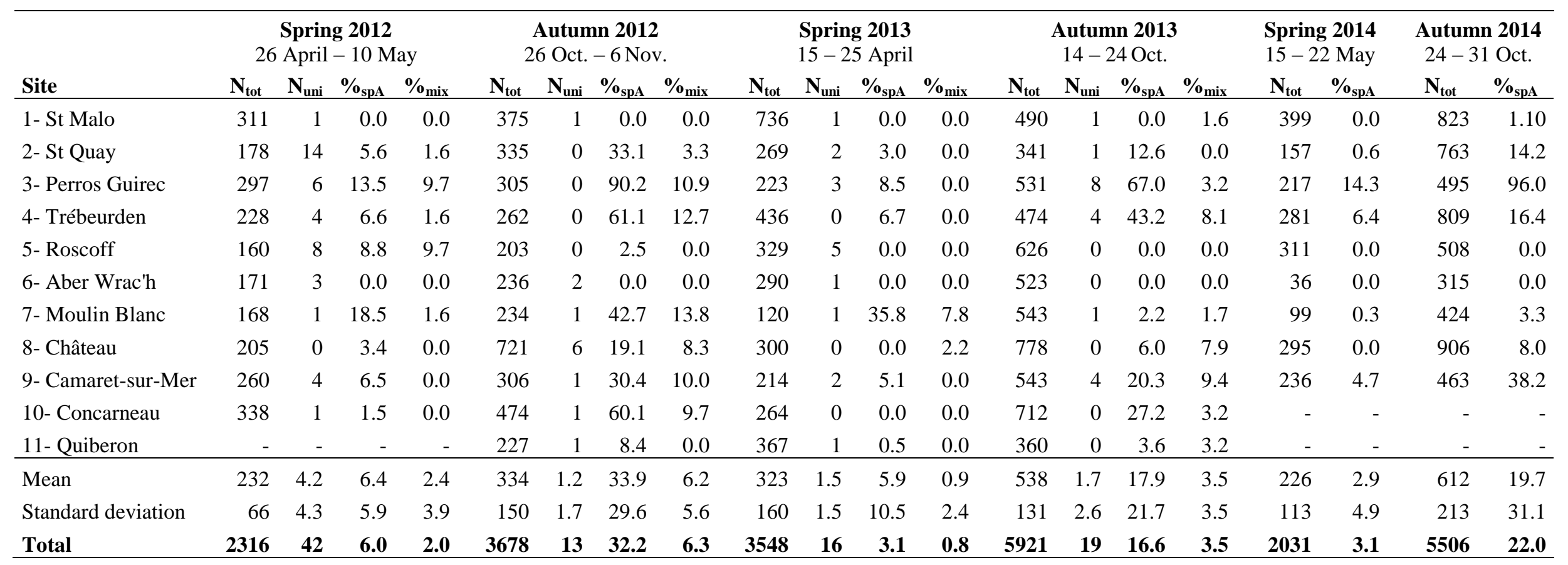


Table 2. Proportion of admixed individuals, i.e. individuals showing a mixture of alleles diagnostic for Ciona intestinalis species A and C. intestinalis species $\mathrm{B}$, for each maternal lineage separately $\left(\%_{\operatorname{mix~spA}}\right.$ and $\%_{\text {mix spB }}$ for individuals diagnosed with species $\mathrm{A}$ mitochondria and a species B mitochondria, respectively), for each site and sampling date studied in 2012 and 2013. $\mathrm{N}_{\mathrm{spA}}$ and $\mathrm{N}_{\mathrm{spB}}$ are the number of specimens for which admixture was examined.

\begin{tabular}{|c|c|c|c|c|c|c|c|c|c|c|c|c|c|c|c|c|}
\hline \multirow[b]{2}{*}{ Site } & \multicolumn{4}{|c|}{ Spring 2012} & \multicolumn{4}{|c|}{ Autumn 2012} & \multicolumn{4}{|c|}{ Spring 2013} & \multicolumn{4}{|c|}{ Autumn 2013} \\
\hline & $\mathbf{N}_{\mathrm{spA}}$ & $\%_{\text {mix spA }}$ & $\mathbf{N}_{\mathrm{spB}}$ & $\%_{\text {mix spB }}$ & $\mathbf{N}_{\mathrm{spA}}$ & $\%_{\text {mix spA }}$ & $\mathbf{N}_{\mathrm{spB}}$ & $\%_{\text {mix spB }}$ & $\mathbf{N}_{\mathrm{spA}}$ & $\%_{\text {mix spA }}$ & $\mathbf{N}_{\mathrm{spB}}$ & $\%_{\text {mix spB }}$ & $\mathbf{N}_{\text {spA }}$ & $\%_{\text {mix spA }}$ & $\mathbf{N}_{\mathrm{spB}}$ & $\%_{\text {mix spB }}$ \\
\hline 1- St Malo & 0 & - & 56 & 0.0 & 0 & - & 62 & 0.0 & 0 & - & 60 & 0.0 & 0 & - & 64 & 1.6 \\
\hline 2- St Quay & 5 & 20.0 & 58 & 0.0 & 28 & 7.1 & 33 & 0.0 & 2 & 0.0 & 55 & 0.0 & 19 & 0.0 & 44 & 0.0 \\
\hline 4- Trébeurden & 4 & 25.0 & 59 & 0.0 & 40 & 15.0 & 23 & 8.7 & 5 & 0.0 & 54 & 0.0 & 29 & 10.3 & 33 & 6.1 \\
\hline 5- Roscoff & 5 & 40.0 & 26 & 3.8 & 1 & 0.0 & 57 & 0.0 & 0 & - & 77 & 0.0 & 0 & - & 60 & 0.0 \\
\hline 6- Aber Wrac'h & 0 & - & 62 & 0.0 & 0 & - & 58 & 0.0 & 0 & - & 63 & 0.0 & 0 & - & 62 & 0.0 \\
\hline 8- Château & 0 & - & 64 & 0.0 & 23 & 21.7 & 37 & 0.0 & 0 & - & 46 & 2.2 & 6 & 16.7 & 57 & 7.0 \\
\hline 9- Camaret-sur-Mer & 8 & 0.0 & 56 & 0.0 & 28 & 17.9 & 32 & 3.1 & 3 & 0.0 & 46 & 0.0 & 17 & 29.4 & 47 & 2.1 \\
\hline 10- Concarneau & 1 & 0.0 & 63 & 0.0 & 48 & 12.5 & 14 & 0.0 & 0 & - & 60 & 0.0 & 20 & 5.0 & 42 & 2.4 \\
\hline 11- Quiberon & - & - & - & - & 5 & 0.0 & 59 & 0.0 & 0 & - & 55 & 0.0 & 5 & 40.0 & 56 & 0.0 \\
\hline Mean & 5.2 & 18.2 & 53.9 & 0.4 & 23.8 & 11.7 & 37.1 & 1.8 & 3.0 & 4.2 & 53.8 & 0.2 & 13.6 & 17.3 & 48.5 & 1.7 \\
\hline Standard deviation & 5.8 & 15.8 & 11.5 & 1.2 & 20.0 & 7.8 & 19.2 & 3.4 & 5.6 & 9.4 & 11.8 & 0.7 & 15.6 & 15.1 & 15.4 & 2.6 \\
\hline
\end{tabular}


Table 3. Results of linear mixed models testing a) the effects of season and sampling year on the relative abundance of Ciona intestinalis species A and C. intestinalis species B in syntopic localities and b) the effect of cross type on the fertilization rate. Degrees of freedom (d.f.), residual d.f., residual deviation and $P$-value (from Chi-squared test) are given. Significant $P$ values are shown in italics.

Variable Model d.f. Residual d.f. Residual deviation $P$-value

a) Relative species abundance

Null model

Year

Season

Year x Season

Null model

Cross type
105

100
2968.1

$2804.9<0.01$

$1667.9<0.001$

$1319.2<0.001$

b) Fertilization rate

5

720.85

$203.44<0.001$ 


\section{Figure Legends}

Figure 1. Artificial plastic substrates are heavily colonized in the study area, including by Ciona intestinalis species A (white form) and C. intestinalis species B (with yellow rim around siphons) as shown in this picture, which also illustrates the syntopy between the two study species. Photo credit: Wilfried Thomas, Station Biologique of Roscoff.

Figure 2. Relative abundance of Ciona intestinalis species A (in black) and species B (in gray) in the 11 study sites (1: St Malo, 2: St Quay, 3: Perros Guirec, 4: Trébeurden, 5: Roscoff, 6: Aber Wrac'h, 7: Moulin Blanc, 8: Château, 9: Camaret-sur-Mer, 10: Concarneau, 11: Quiberon) from spring 2012 to autumn 2014. Maps with the same letter indicate nonsignificant differences between sampling dates (pairwise comparisons, $P>0.05$ ).

Figure 3. Ternary diagrams representing the proportion of the three recorded reproductive stages for Ciona intestinalis species A (black circles) and for species B (gray circles), for each sampling date. Numbers in the circles refer to site numbers (see Table 1).

Figure 4. Fertilization rate for conspecific crosses (i.e. using female (Fe) and male (Ma) gametes of the same species, gray bars), heterospecific crosses (i.e. using female and male gametes from different species, white bars) and self-crosses (i.e. using gametes from the same individual, black bars). Values with the same letter are not significantly different (pairwise comparisons, $P>0.05)$.

Figure 5. Hybrid index computed for each sampling date for individuals with a Ciona intestinalis species A (black bars) and C. intestinalis species B (gray bars) maternal lineage. 
Maternal lineage was ascertained with a diagnostic mitochondrial marker (see text). $\mathrm{N}_{\mathrm{spA}}$ and $\mathrm{N}_{\mathrm{spB}}$ are the number of specimens examined. The individual (sampled in autumn 2013) indicated by an arrow has a hybrid index of 3 and is the only putative F1 hybrid found of the 3,048 study individuals. 
Figure 1.

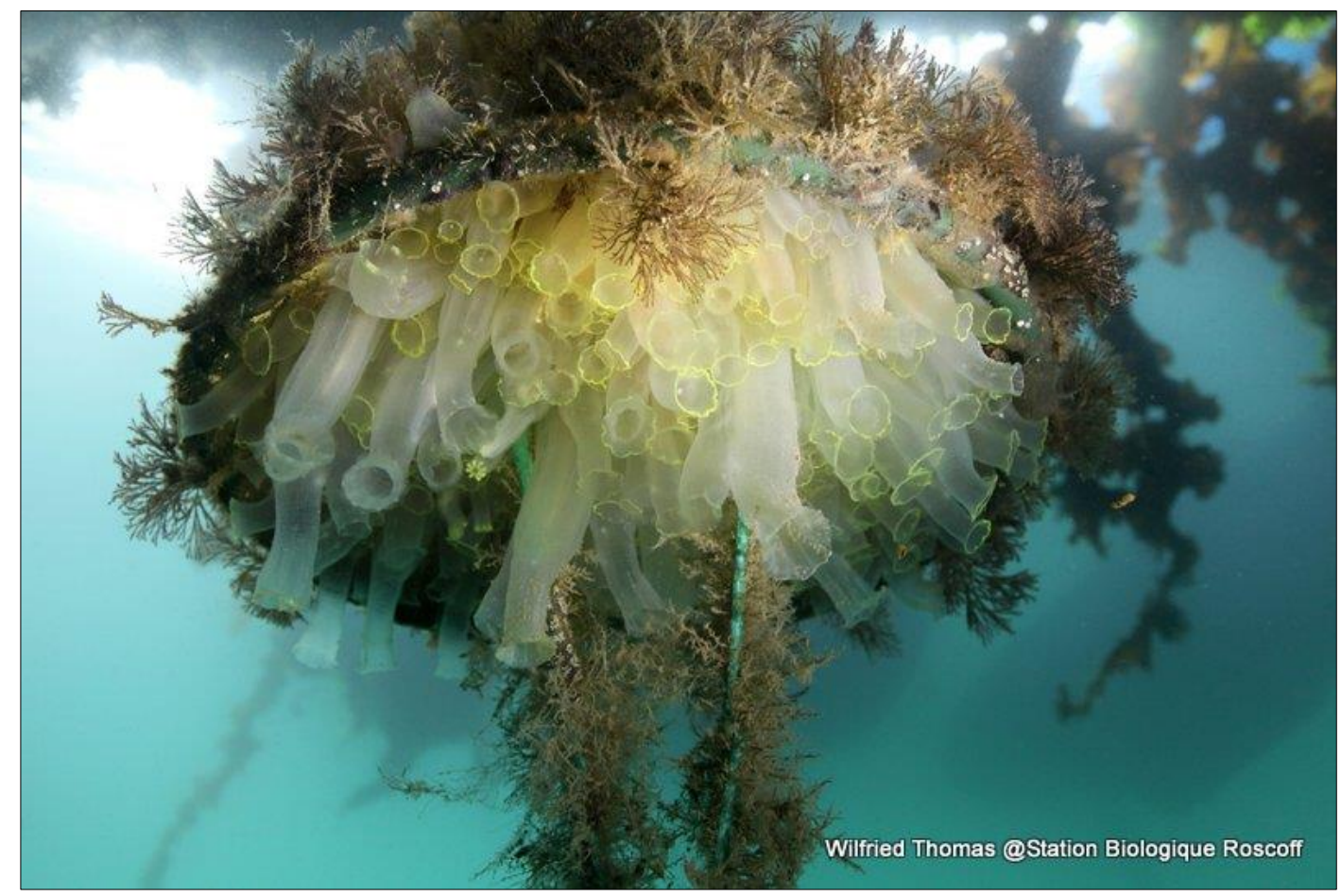


Figure 2.

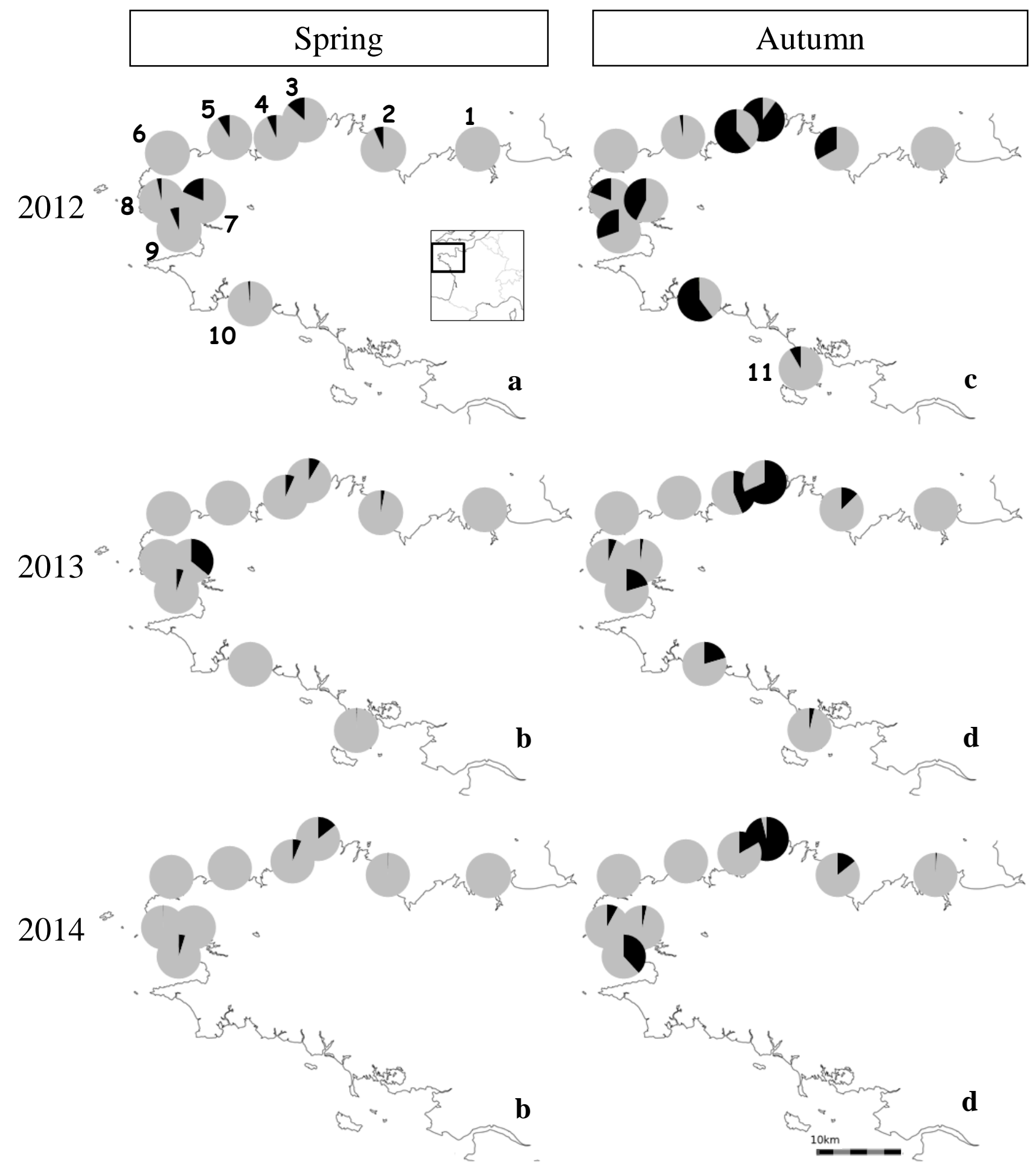


Figure 3.
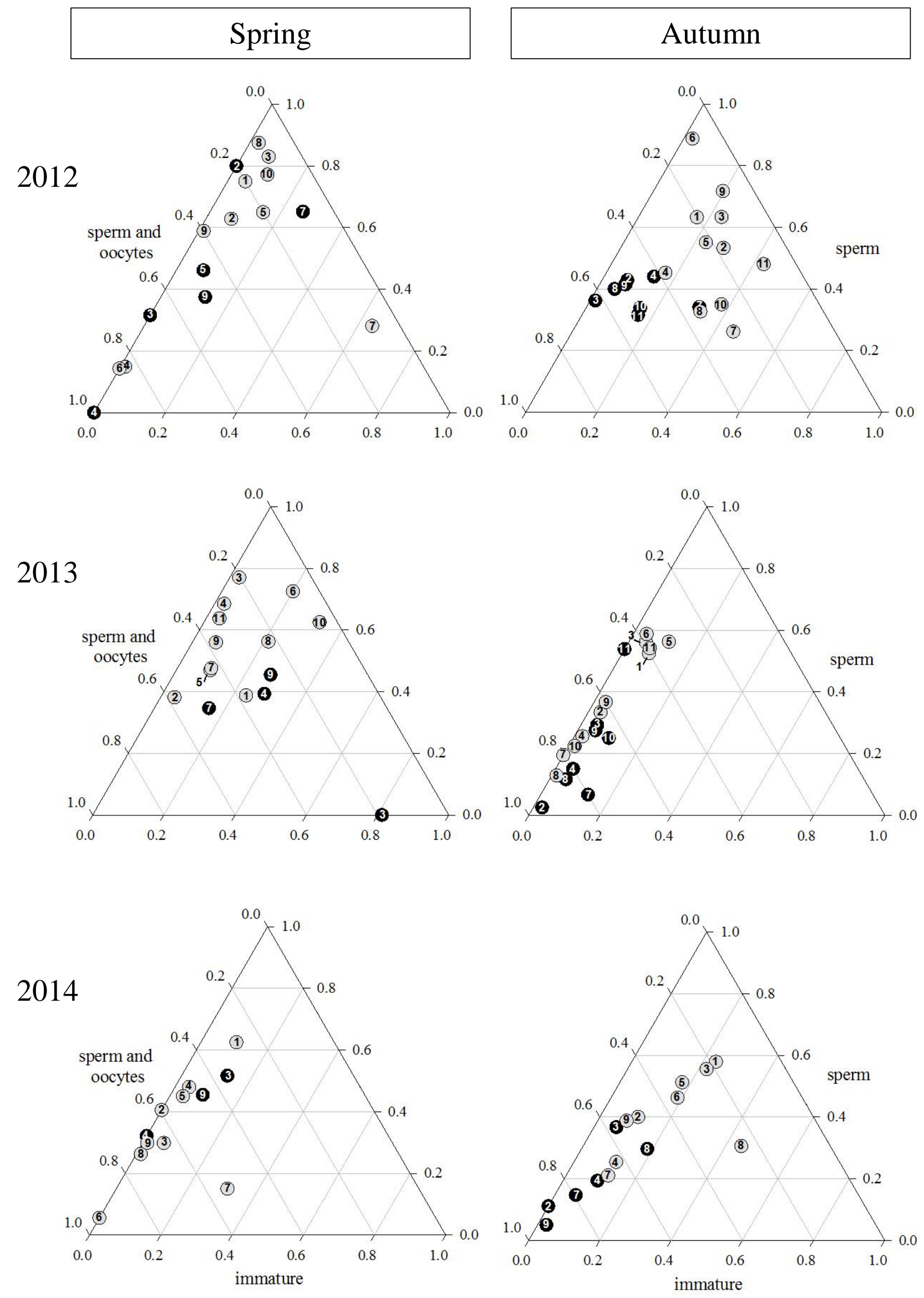
Figure 4.

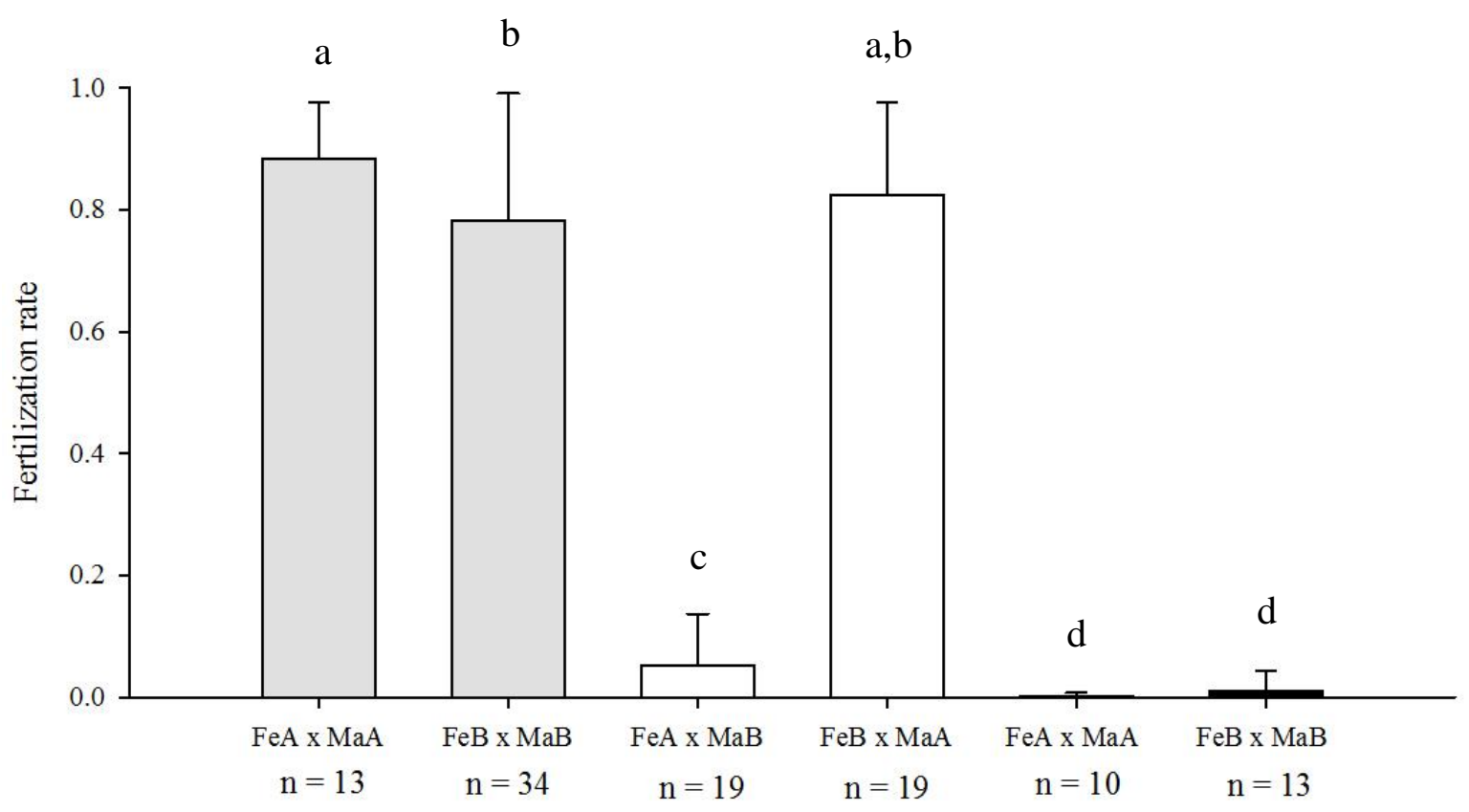


Figure 5.

Spring
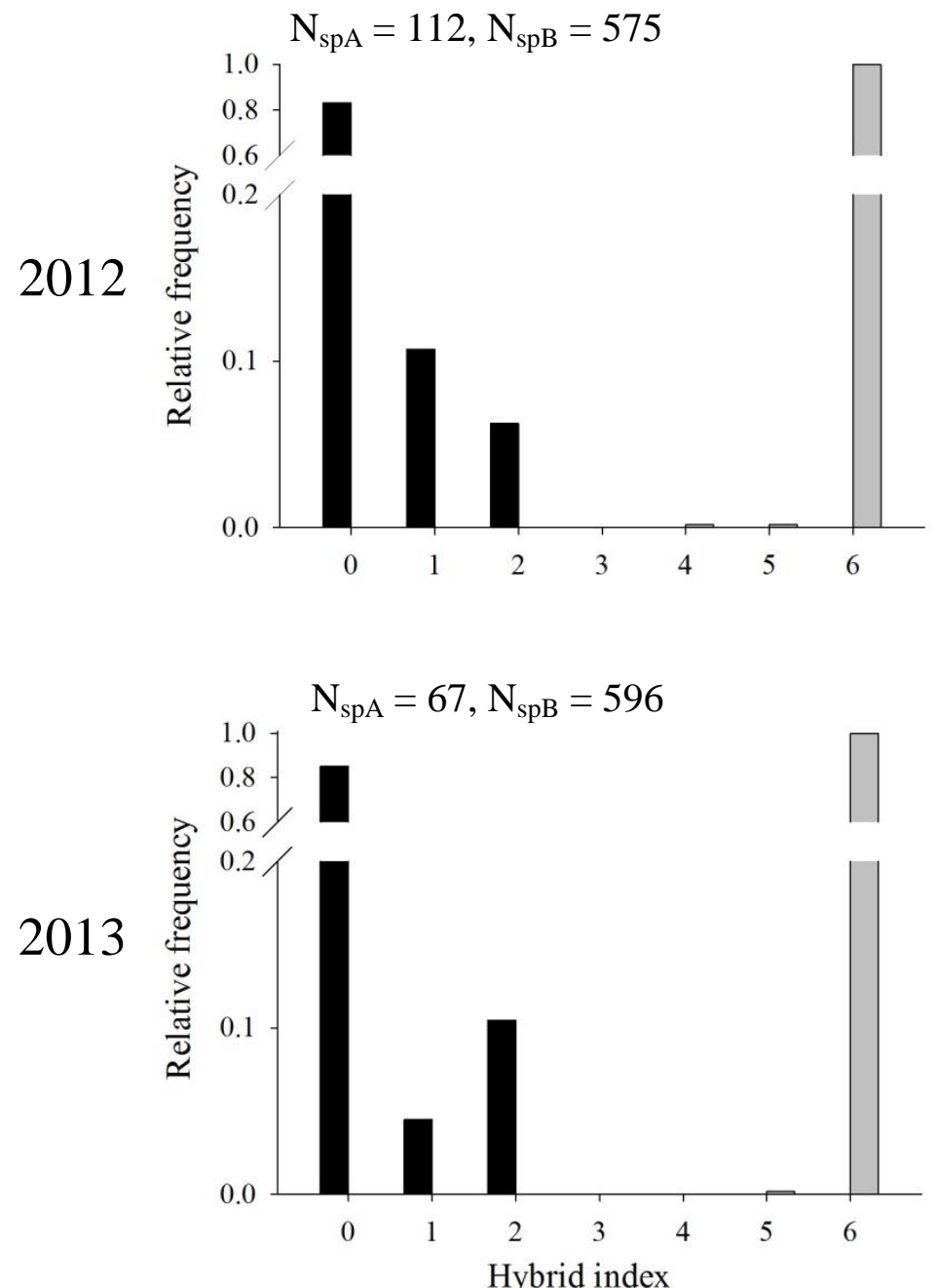

Autumn

$\mathrm{N}_{\mathrm{spA}}=326, \mathrm{~N}_{\mathrm{spB}}=507$

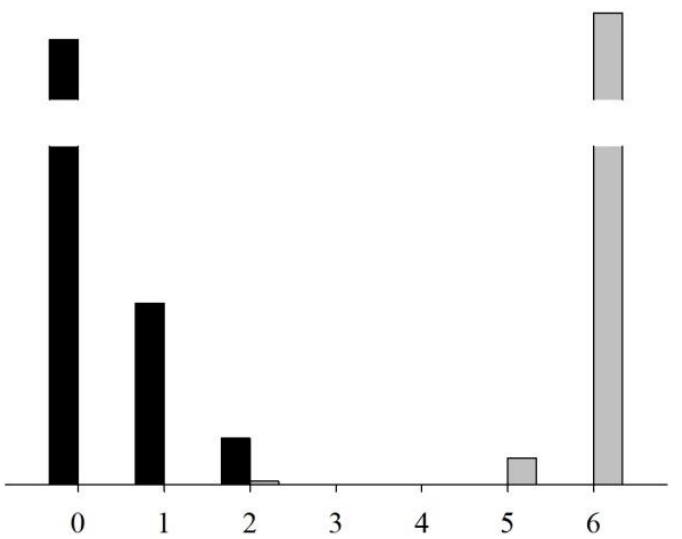

$\mathrm{N}_{\mathrm{spA}}=277, \mathrm{~N}_{\mathrm{spB}}=588$

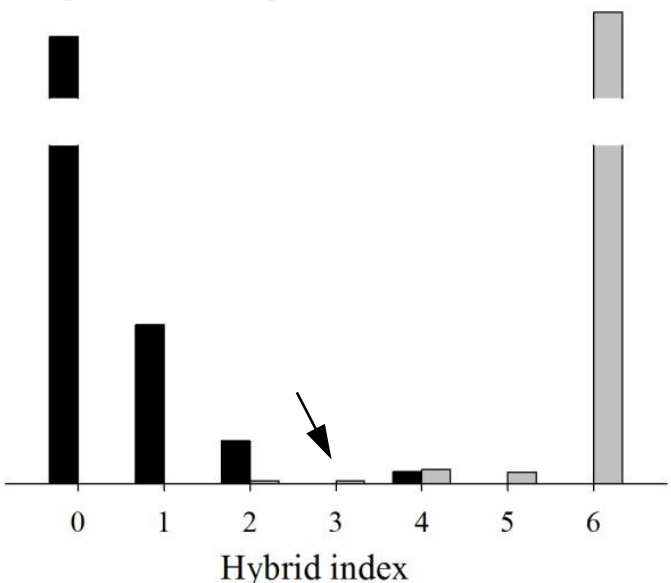




\section{Supplementary Information for online appendix}

Table S1. Geographical coordinates and characteristics of each site, i.e. open or closed marinas (by means of tidal or sill gates) at low tide, freshwater (estuarine) or marine influence.

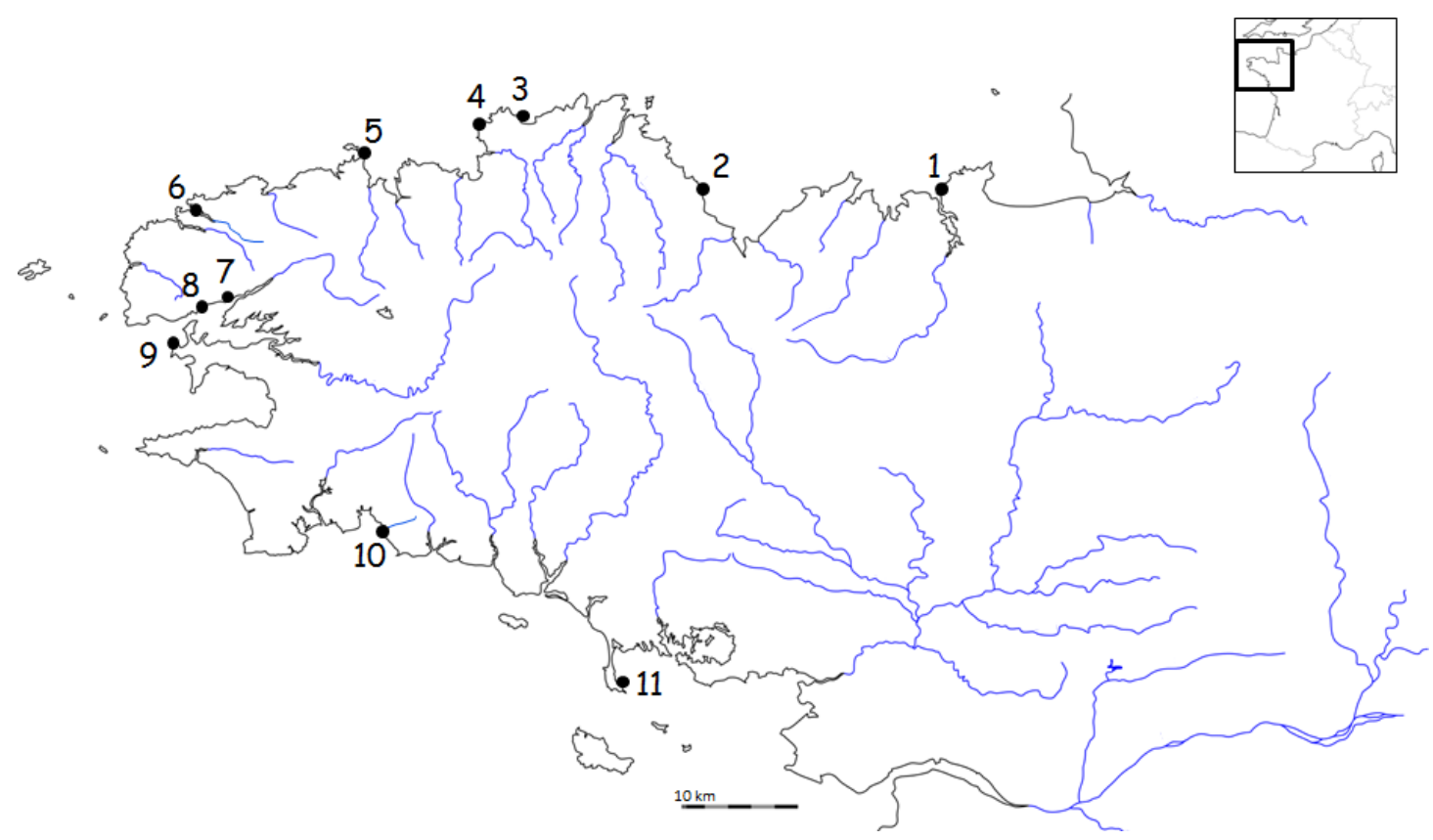

\begin{tabular}{lrrr}
\hline Site & Coordinates & Open/ Closed & Estuarine/Marine \\
\hline 1- St Malo & $48.638617 ;-2.026411$ & Open & Marine \\
2- St Quay & $48.646136 ;-2.820925$ & Open & Marine \\
3- Perros Guirec & $48.804877 ;-3.441954$ & Closed & Marine \\
4- Trébeurden & $48.769510 ;-3.585811$ & Closed & Marine \\
5- Roscoff & $48.717500 ;-3.965401$ & Open & Marine \\
6- Aber Wrac'h & $48.598626 ;-4.562438$ & Open & Estuarine \\
7- Moulin Blanc & $48.390365 ;-4.432140$ & Open & Estuarine \\
8- Château & $48.379489 ;-4.489469$ & Open & Estuarine \\
9- Camaret-sur-Mer & $48.279674 ;-4.596113$ & Open & Marine \\
10- Concarneau & $47.870150 ;-3.914604$ & Open & Estuarine \\
11- Quiberon & $47.488223 ;-3.103269$ & Open & Marine \\
\hline
\end{tabular}


Table S2. Detailed sampling size used for analyzing the reproductive status and proportions of the observed reproductive stages for $C$. intestinalis species $\mathrm{A}\left(\mathrm{N}_{\mathrm{spA}}\right)$ and species $\mathrm{B}\left(\mathrm{N}_{\mathrm{spB}}\right)$ at each study site and sampling date. Three categories were recorded: 1) immature individuals (imm), 2) individuals with sperm only (sp) and 3) individuals with both sperm and oocytes $(\mathrm{sp}+\mathrm{ooc})$.

A) Spring 2012

\begin{tabular}{lrrrrrrrr}
\hline & \multicolumn{4}{c}{ Species A } & \multicolumn{4}{c}{ Species B } \\
Site & $\mathbf{N}_{\text {spA }}$ & \%imm & \% sp & \% sp+ooc & $\mathbf{N}_{\mathbf{s p B}}$ & \%imm & \%sp & \%sp+ooc \\
\hline 1- St Malo & 0 & - & - & - & 80 & 5.0 & 75.0 & 20.0 \\
2- St Quay & 10 & 0.0 & 80.0 & 20.0 & 70 & 7.1 & 62.9 & 30.0 \\
3- Perros Guirec & 38 & 0.0 & 31.6 & 68.4 & 53 & 7.5 & 83.0 & 9.4 \\
4- Trébeurden & 15 & 0.0 & 0.0 & 100.0 & 74 & 1.4 & 14.9 & 83.8 \\
5- Roscoff & 13 & 7.7 & 46.2 & 46.2 & 40 & 15.0 & 65.0 & 20.0 \\
6- Aber Wrac'h & 0 & - & - & - & 77 & 0.0 & 14.3 & 85.7 \\
7- Moulin Blanc & 23 & 26.1 & 65.2 & 8.7 & 64 & 64.1 & 28.1 & 7.8 \\
8- Château & 7 & 0.0 & 71.4 & 28.6 & 80 & 2.5 & 87.5 & 10.0 \\
9- Camaret-sur-Mer & 16 & 12.5 & 37.5 & 50.0 & 73 & 1.4 & 58.9 & 39.7 \\
10- Concarneau & 5 & 0.0 & 20.0 & 80.0 & 79 & 10.1 & 77.2 & 12.7 \\
11- Quiberon & - & - & - & - & - & - & - & - \\
\hline Mean & 12.7 & 5.8 & 44.0 & 50.2 & 69 & 11.4 & 56.7 & 31.9 \\
Standard deviation & 11.5 & 9.5 & 27.3 & 31.2 & 13.2 & 19.1 & 27.6 & 29.6 \\
Total & $\mathbf{1 2 7}$ & $\mathbf{7 . 1}$ & $\mathbf{4 1 . 7}$ & $\mathbf{5 1 . 2}$ & $\mathbf{6 9 0}$ & $\mathbf{1 0 . 4}$ & $\mathbf{5 6 . 2}$ & $\mathbf{3 3 . 3}$ \\
\hline
\end{tabular}

B) Autumn 2012

\section{Species A $\quad$ Species B}

\begin{tabular}{lrrrrrrrr} 
Site & $\mathbf{N}_{\mathbf{s p A}}$ & \%imm & \%sp & \% sp+ooc & $\mathbf{N}_{\mathbf{s p B}}$ & $\mathbf{\%} \mathbf{i m m}$ & $\mathbf{\% s p}$ & $\mathbf{\%} \mathbf{s p + o o c}$ \\
\hline 1- St Malo & 0 & - & - & - & 79 & 16.5 & 63.3 & 20.3 \\
2- St Quay & 42 & 7.1 & 42.9 & 50.0 & 45 & 28.9 & 53.3 & 17.8 \\
3- Perros Guirec & 69 & 1.4 & 36.2 & 62.3 & 30 & 23.3 & 63.3 & 13.3 \\
4- Trébeurden & 50 & 14.0 & 44.0 & 42.0 & 42 & 16.7 & 45.2 & 38.1 \\
5- Roscoff & 5 & 20.0 & 60.0 & 20.0 & 78 & 23.1 & 55.1 & 21.8 \\
6- Aber Wrac'h & 0 & - & - & - & 80 & 2.5 & 88.8 & 8.8 \\
7- Moulin Blanc & 41 & 31.7 & 34.1 & 34.1 & 42 & 45.2 & 26.2 & 28.6 \\
8- Château & 40 & 5.0 & 40.0 & 55.0 & 55 & 32.7 & 32.7 & 34.5 \\
9- Camaret-sur-Mer & 41 & 7.3 & 41.5 & 51.2 & 46 & 19.6 & 71.7 & 8.7 \\
10- Concarneau & 59 & 15.3 & 33.9 & 50.8 & 40 & 37.5 & 35.0 & 27.5 \\
11- Quiberon & 19 & 15.8 & 31.6 & 52.6 & 77 & 42.9 & 48.1 & 9.1 \\
\hline Mean & 33.3 & 13.1 & 40.5 & 46.5 & 55.8 & 26.3 & 53.0 & 20.8 \\
Standard deviation & 23.8 & 9.2 & 8.5 & 12.7 & 18.9 & 12.8 & 18.4 & 10.4 \\
Total & $\mathbf{3 6 6}$ & $\mathbf{1 1 . 5}$ & $\mathbf{3 8 . 5}$ & $\mathbf{5 0 . 0}$ & $\mathbf{6 1 4}$ & $\mathbf{2 5 . 1}$ & $\mathbf{5 5 . 2}$ & $\mathbf{1 9 . 7}$ \\
\hline
\end{tabular}




\begin{tabular}{lrrrrrrrr}
\hline & \multicolumn{4}{c}{ Species A } & \multicolumn{4}{c}{ Species B } \\
Site & $\mathbf{N}_{\text {spd }}$ & \%imm & \%sp & \% sp+ooc & $\mathbf{N}_{\text {spB }}$ & \%imm & \%sp & \%sp+ooc \\
\hline 1- St Malo & 0 & - & - & - & 80 & 23.8 & 38.8 & 37.5 \\
2- St Quay & 6 & 33.3 & 16.7 & 50.0 & 76 & 3.9 & 38.2 & 57.9 \\
3- Perros Guirec & 16 & 81.3 & 0.0 & 18.8 & 74 & 2.7 & 77.0 & 20.3 \\
4- Trébeurden & 28 & 28.6 & 39.3 & 32.1 & 73 & 2.7 & 68.5 & 28.8 \\
5- Roscoff & 0 & - & - & - & 115 & 9.6 & 47.0 & 43.5 \\
6- Aber Wrac'h & 0 & - & - & - & 80 & 20.0 & 72.5 & 7.5 \\
7- Moulin Blanc & 26 & 15.4 & 34.6 & 50.0 & 42 & 9.5 & 47.6 & 42.9 \\
8- Château & 0 & - & - & - & 80 & 21.3 & 56.3 & 22.5 \\
9- Camaret-sur-Mer & 11 & 27.3 & 45.5 & 27.3 & 75 & 6.7 & 56.0 & 37.3 \\
10- Concarneau & 0 & - & - & - & 80 & 32.5 & 62.5 & 5.0 \\
11- Quiberon & 2 & 0.0 & 0.0 & 100.0 & 80 & 3.8 & 63.8 & 32.5 \\
\hline Mean & 8.1 & 31.0 & 22.7 & 46.4 & 77.7 & 12.4 & 57.1 & 30.5 \\
Standard deviation & 10.8 & 27.4 & 20.0 & 29.1 & 16.5 & 10.3 & 13.1 & 15.9 \\
Total & $\mathbf{8 9}$ & $\mathbf{3 3 . 7}$ & $\mathbf{2 9 . 2}$ & $\mathbf{3 7 . 1}$ & $\mathbf{8 5 5}$ & $\mathbf{1 2 . 6}$ & $\mathbf{5 7 . 0}$ & $\mathbf{3 0 . 4}$ \\
\hline
\end{tabular}

D) Autumn 2013

\begin{tabular}{|c|c|c|c|c|c|c|c|c|}
\hline \multirow[b]{2}{*}{ Site } & \multicolumn{4}{|c|}{ Species A } & \multicolumn{4}{|c|}{ Species B } \\
\hline & $\mathbf{N}_{\mathrm{spA}}$ & $\%$ imm & $\%$ sp & $\%$ sp+ooc & $\mathbf{N}_{\mathrm{spB}}$ & $\%$ imm & $\%$ sp & $\% \mathrm{sp}+\mathrm{ooc}$ \\
\hline 1- St Malo & 0 & - & - & - & 80 & 7.5 & 52.5 & 40.0 \\
\hline 2- St Quay & 40 & 2.5 & 2.5 & 95.0 & 57 & 3.5 & 33.3 & 63.2 \\
\hline 3- Perros Guirec & 65 & 4.6 & 29.2 & 66.2 & 41 & 4.9 & 56.1 & 39.0 \\
\hline 4- Trébeurden & 40 & 5.0 & 15.0 & 80.0 & 43 & 2.3 & 25.6 & 72.1 \\
\hline 5- Roscoff & 0 & - & - & - & 80 & 11.3 & 56.3 & 32.5 \\
\hline 6- Aber Wrac'h & 0 & - & - & - & 80 & 3.8 & 58.8 & 37.5 \\
\hline 7- Moulin Blanc & 15 & 13.3 & 6.7 & 80.0 & 77 & 0.0 & 19.5 & 80.5 \\
\hline 8- Château & 43 & 4.7 & 11.6 & 83.7 & 70 & 1.4 & 12.9 & 85.7 \\
\hline 9- Camaret-sur-Mer & 40 & 5.0 & 27.5 & 67.5 & 60 & 3.3 & 36.7 & 60.0 \\
\hline 10- Concarneau & 40 & 10.0 & 25.0 & 65.0 & 58 & 1.7 & 22.4 & 75.9 \\
\hline 11- Quiberon & 13 & 0.0 & 53.8 & 46.2 & 72 & 6.9 & 54.2 & 38.9 \\
\hline Mean & 26.9 & 5.0 & 19.5 & 75.5 & 65.3 & 4.2 & 38.9 & 56.8 \\
\hline Standard deviation & 22.1 & 4.3 & 16.4 & 15.9 & 14.5 & 3.2 & 17.2 & 19.8 \\
\hline Total & 296 & 5.0 & 19.0 & 76.0 & 718 & 4.5 & 39.7 & 55.8 \\
\hline
\end{tabular}

E) Spring 2014

\begin{tabular}{|c|c|c|c|c|c|c|c|c|}
\hline \multirow[b]{2}{*}{ Site } & \multicolumn{4}{|c|}{ Species A } & \multicolumn{4}{|c|}{ Species B } \\
\hline & $\mathbf{N}_{\mathrm{spA}}$ & $\%$ imm & $\%$ sp & $\%$ sp+ooc & $\mathbf{N}_{\mathrm{spB}}$ & $\%$ imm & $\%$ sp & $\% \mathrm{sp}+\mathrm{ooc}$ \\
\hline 1- St Malo & 0 & - & - & - & 80 & 10.0 & 62.5 & 27.5 \\
\hline 2- St Quay & 4 & 0.0 & 25.0 & 75.0 & 79 & 0.0 & 40.5 & 59.5 \\
\hline 3- Perros Guirec & 31 & 12.9 & 51.6 & 35.5 & 67 & 6.0 & 29.9 & 64.2 \\
\hline 4- Trébeurden & 28 & 0.0 & 32.1 & 67.9 & 75 & 4.0 & 48.0 & 48.0 \\
\hline 5- Roscoff & 0 & - & - & - & 80 & 3.8 & 45.0 & 51.3 \\
\hline 6- Aber Wrac'h & 0 & - & - & - & 36 & 0.0 & 5.6 & 94.4 \\
\hline 7- Moulin Blanc & 0 & - & - & - & 80 & 31.3 & 15.0 & 53.8 \\
\hline 8- Château & 1 & 0.0 & 0.0 & 100.0 & 80 & 1.3 & 26.3 & 72.5 \\
\hline 9- Camaret-sur-Mer & 11 & 9.1 & 45.5 & 45.5 & 77 & 1.3 & 29.9 & 68.8 \\
\hline 10- Concarneau & - & - & - & - & - & - & - & - \\
\hline 11- Quiberon & - & - & - & - & - & - & - & - \\
\hline Mean & 8.3 & 4.4 & 30.8 & 64.8 & 72.7 & 6.4 & 33.6 & 60.0 \\
\hline Standard deviation & 12.5 & 6.2 & 20.2 & 25.4 & 14.4 & 9.9 & 17.4 & 18.6 \\
\hline Total & 75 & 6.7 & 41.3 & 52.0 & 654 & 6.9 & 35.5 & 57.6 \\
\hline
\end{tabular}


F) Autumn 2014

\begin{tabular}{|c|c|c|c|c|c|c|c|c|}
\hline \multirow[b]{2}{*}{ Site } & \multicolumn{4}{|c|}{ Species A } & \multicolumn{4}{|c|}{ Species B } \\
\hline & $\mathbf{N}_{\text {spA }}$ & \%imm & $\%$ sp & $\%$ sp+ooc & $\mathbf{N}_{\mathrm{spB}}$ & $\%$ imm & $\%$ sp & $\% \mathrm{sp}+\mathrm{ooc}$ \\
\hline 1- St Malo & 9 & 11.1 & 55.6 & 33.3 & 76 & 23.7 & 57.9 & 18.4 \\
\hline 2- St Quay & 27 & 0.0 & 11.1 & 88.9 & 65 & 10.8 & 40.0 & 49.2 \\
\hline 3- Perros Guirec & 79 & 6.3 & 36.7 & 57.0 & 27 & 22.2 & 55.6 & 22.2 \\
\hline 4- Trébeurden & 31 & 9.7 & 19.4 & 71.0 & 59 & 11.9 & 25.4 & 62.7 \\
\hline 5- Roscoff & 0 & - & - & - & 80 & 17.5 & 51.3 & 31.3 \\
\hline 6- Aber Wrac'h & 0 & - & - & - & 80 & 18.8 & 46.3 & 35.0 \\
\hline 7- Moulin Blanc & 34 & 5.9 & 14.7 & 79.4 & 76 & 11.8 & 21.1 & 67.1 \\
\hline 8- Château & 27 & 18.5 & 29.6 & 51.9 & 72 & 44.4 & 30.6 & 25.0 \\
\hline 9- Camaret-sur-Mer & 40 & 2.5 & 5.0 & 92.5 & 49 & 8.2 & 38.8 & 53.1 \\
\hline 10- Concarneau & - & - & - & - & - & - & - & - \\
\hline 11- Quiberon & - & - & - & - & - & - & - & \\
\hline Mean & 27.4 & 7.4 & 25.3 & 67.3 & 64.9 & 18.8 & 40.8 & 40.4 \\
\hline Standard deviation & 24.3 & 6.0 & 19.0 & 22.2 & 17.6 & 11.0 & 13.2 & 18.1 \\
\hline Total & 247 & 6.9 & 25.7 & 67.4 & 584 & 19.2 & 40.2 & 40.6 \\
\hline
\end{tabular}


Table S3. Proportions of admixture per locus, sampling date and maternal lineage (i.e. identified with one species-diagnostic mitochondrial marker) for the 131 individuals that showed an admixed multilocus genotype with the three nuclear loci scored (i.e. CesA, Hox 5 and vAChTP).

\begin{tabular}{lcrrrr}
\hline Generation & $\begin{array}{l}\text { Maternal } \\
\text { Lineage } \\
\text { (mtDNA) }\end{array}$ & $\mathbf{N}_{\text {ind }}$ & \% CesA & \%Hox5 & \%vAChTP \\
\hline Spring 2012 & sp A & 19 & 5.2 & 89.5 & 5.2 \\
& sp B & 2 & 100.0 & 0.0 & 0.0 \\
Autumn 2012 & sp A & 44 & 2.3 & 97.7 & 0.0 \\
& sp B & 9 & 88.8 & 11.1 & 11.1 \\
Spring 2013 & sp A & 10 & 0.0 & 100.0 & 0.0 \\
& sp B & 1 & 100.0 & 0.0 & 0.0 \\
Autumn 2013 & sp A & 35 & 17.1 & 82.9 & 5.7 \\
& sp B & 11 & 100.0 & 27.3 & 9.1 \\
\hline
\end{tabular}


Figure S1. Monthly mean of seawater temperature $\left({ }^{\circ} \mathrm{C}\right)$ recorded for this study using data loggers $\left(\right.$ Tidbi $^{\circledR}{ }_{\mathrm{v} 2}$ ) located at $1.5 \mathrm{~m}$ depth in most of the studied marinas (all except nos. 1 , 2, 10, 11, in Fig. 2 in the main text).
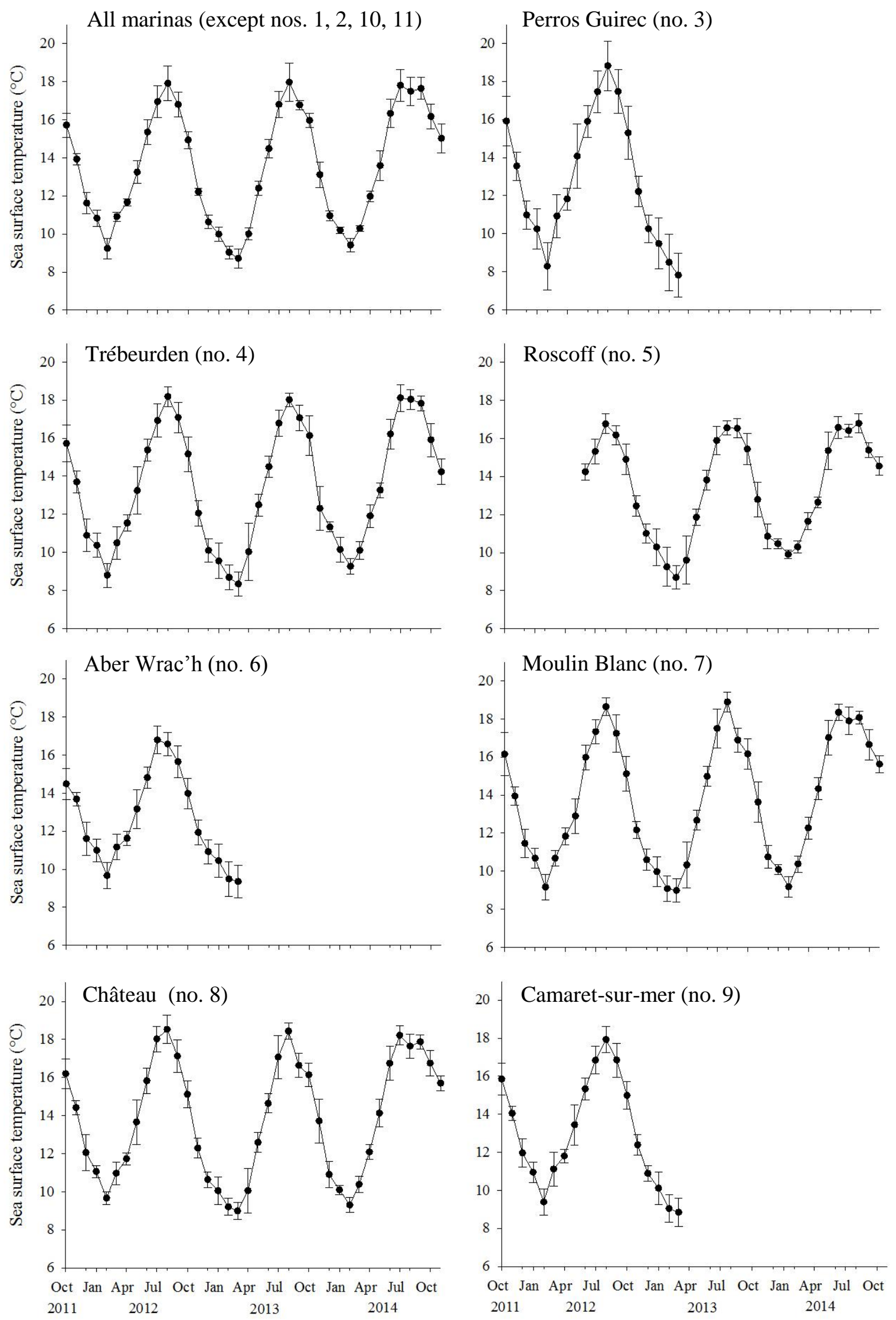
Figure S2. Salinity values and abundance of $C$. intestinalis spp. recorded in Moulin Blanc (no. 7 in Fig. 2 in the main text) between November 2012 and December 2014. Each month, salinity was recorded at two depths $(0.25 \mathrm{~m}$ and $1.5 \mathrm{~m})$ using a Hach Lange HQ40d multimeter equipped with a CDC 40115 conductivity probe. Every three months, the abundance of $C$. intestinalis spp. was estimated by SCUBA divers using a visual census method along ca. $30 \mathrm{~m}$ under one pontoon, according to a semi-quantitative scale $(0=$ absent, $1=0-20 \%, 2=20-40 \%, 3=40-60 \%, 4=60-80 \%$ and $5=80-100 \%$ of coverage $)$.

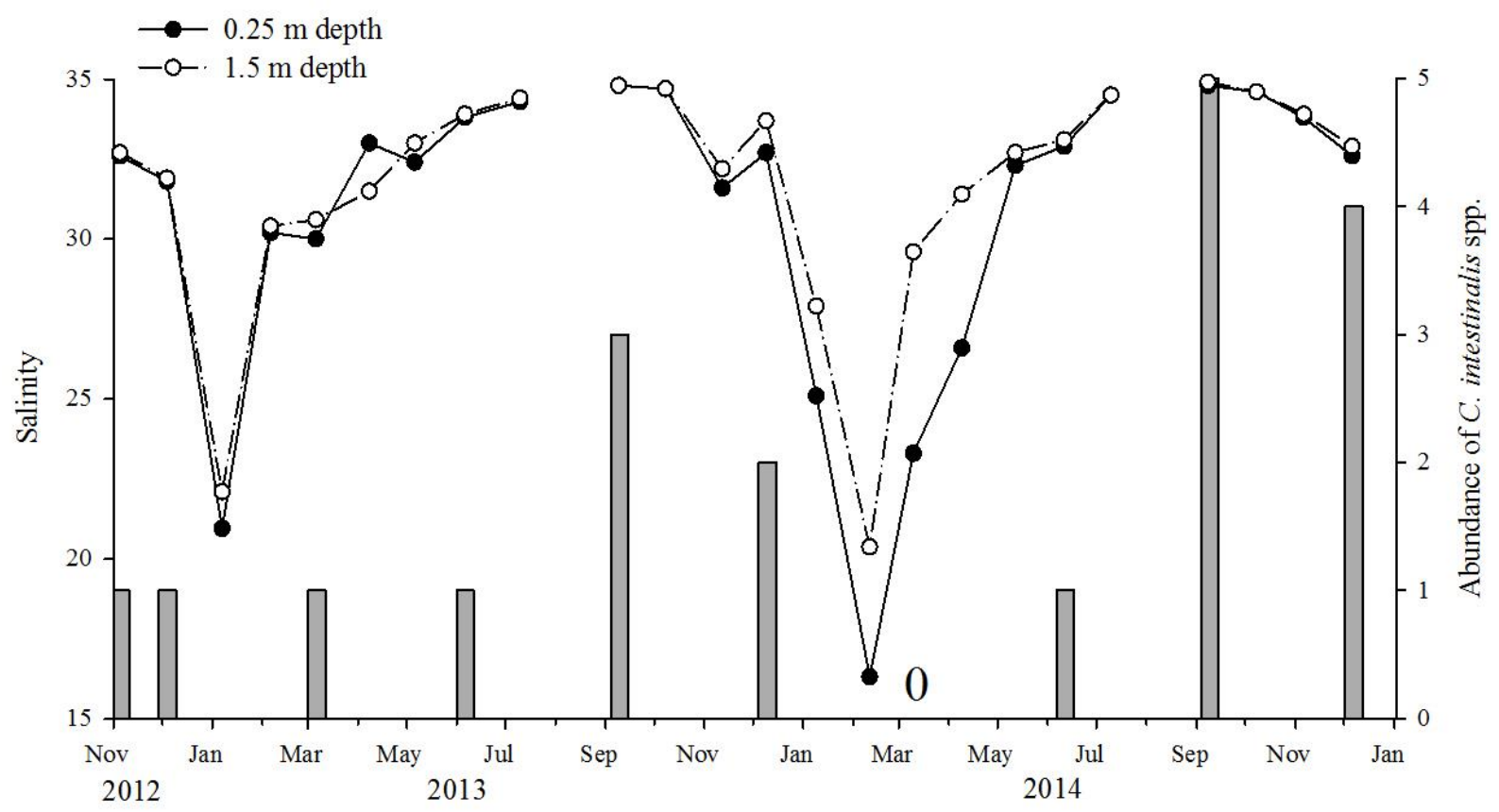

